\title{
New modular organic platform for understanding the effect of structural changes on slow magnetic relaxation in mononuclear octahedral copper(II) complexes
}

$=$ Received 00th January 20xx Accepted 00th January 20xx

DOI: $10.1039 / x 0 x \times 00000 x$

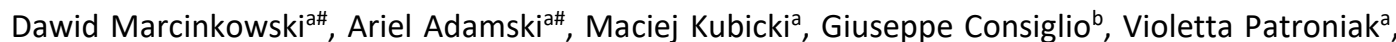
Tomasz Ślusarski ${ }^{a, c}$, Muhammed Açıkgöz ${ }^{d}$, Daria Szeliga ${ }^{e}$, Nahir Vadra a,f, Mirosław Karbowiake, Ireneusz Stefaniukg, Czesław Rudowicz ${ }^{\mathrm{a}}$, Adam Gorczyńskia* and Maria Korabik ${ }^{\mathrm{e} *}$

\section{Introduction}

Molecular nanomagnets (MNMs) are a research focus of scientists due to a variety of potential applications ${ }^{1-4}$, including molecular spintronics ${ }^{1,5,6}$, high-density information storage ${ }^{7-9}$, quantum information processing or sensing. ${ }^{10-16}$ These systems display magnetic hysteresis below their blocking temperature $\left(T_{\mathrm{B}}\right)$ and are magnetically bi-stable, exhibiting an energy barrier to spin reversal $\left(U_{\text {eff }}\right)^{17-22}$, ultimately manifested by macroscopic quantum tunneling and slow relaxation of magnetization. The

\footnotetext{
a. Faculty of Chemistry, Adam Mickiewicz University, Uniwersytetu Poznańskiego 8, 61-614 Poznań

${ }^{b}$ Dipartimento di Scienze Chimiche, Università di Catania, I-95125 Catania, Italy

c Institute of Spintronics and Quantum Information, Faculty of Physics, Adam Mickiewicz University, Uniwersytetu Poznańskiego 2, 61-614 Poznań, Poland

${ }^{d}$ Department of Science, The State University of New York (SUNY) Maritime College, New York 10465, USA

e Faculty of Chemistry, University of Wrocław, F. Joliot-Curie 14, 50-383 Wrocław, Poland

$f$ Universidad de Buenos Aires, Facultad de Ciencias Exactas y Naturales, Departamento de Química Inorgánica, Analítica y Química Física and CONICETUniversidad de Buenos Aires, Instituto de Química Física de los Materiales, Medio Ambiente y Energía (INQUIMAE), Buenos Aires C1428EGA, Argentina

${ }^{g}$ College of Natural Sciences, University of Rzeszow, Rejtana 16a, 35-310 Rzeszow, Poland

\#Ariel Adamski and Dawid Marcinkowski contributed equally. Electronic Supplementary Information (ESI) available: experimental synthetic details, part of magnetic, spectroscopic and theoretical details. See DOI: 10.1039/x0xx00000x
}

archetypal Single Molecule Magnet (SMM) is a dodecanuclear manganese cluster, $\left[\mathrm{Mn}_{12} \mathrm{O}_{12}(\mathrm{OAc})_{16}\left(\mathrm{H}_{2} \mathrm{O}\right)_{4}\right] \cdot 2 \mathrm{MeCO}_{2} \mathrm{H} \cdot 4 \mathrm{H}_{2} \mathrm{O}$, magnetically characterized by R. Sessoli, D. Gatteschi et al., exhibiting $U_{\text {eff }}=60 \mathrm{~K}$ and $T_{\mathrm{B}}=3 \mathrm{~K} .{ }^{23}$ That discovery led to the quest for SMMs with a $T_{\mathrm{B}}$ above room temperature. More recently, research concentrates on monometallic Single Ion Magnets (SIMs) based on the $f-24-27$ and $d$ - block $^{28,} 29$ ions. The highest $T_{\mathrm{B}}$ has been reported by Guo et al. ${ }^{30}$, for organometallic Dy(III) complex displaying magnetic hysteresis at temperatures reaching $80 \mathrm{~K}$. That discovery could facilitate development of SIM devices that function at liquid nitrogen temperatures. However, studies with various Dy(III) congeners of this family ${ }^{31-}$ ${ }^{33}$ show that $U_{\text {eff }}$ and $T_{b}$ are not simply correlated with the Dy- $X$ distance and $\mathrm{X}$-DY-X angle axiality (where $\mathrm{X}-$ donor atom(s)) and indicate the importance of magnetization relaxation mechanisms. ${ }^{4,34-40}$

While similar level of performance for $d$-block SIMs is yet to be achieved, prerequisites for utilization of $3 d$ complexes as molecular nanomagnets is well-established. ${ }^{3,} 41$ Magnetic anisotropy therein results predominantly from the zero field splitting (ZFS) of the ground state of the $d^{n}$ ion-systems with $S>$ $1 / 2 .{ }^{19}$ The ZFS cannot occur for systems with $S=1 / 2$. Hence, slow relaxation of magnetization observed therein is ascribed to more complex mechanisms, including combined phonon, direct 
and Raman processes. ${ }^{42,43}$ Importantly, the $S=1 / 2$ systems are excellent candidates for construction of molecular qubits. ${ }^{44,45}$

To facilitate the desired molecular magnetic behavior in $S=$ $1 / 2$ coordination systems, the following molecular design criteria are preferred: (i) square planar coordination geometry; (ii) coordinating atoms devoid of nuclear spin; (iii) rigidification of the molecular architecture; (iv) minimization of the protons influence above a certain radius from the metal (the concept of spin diffusion barrier). ${ }^{14,46-48}$ Chosen examples of $d^{\text {n }}$ systems with $\mathrm{S}=1 / 2$ based on $\mathrm{V}(\mathrm{IV})^{63,74-80}, \mathrm{Fe}(\mathrm{V})^{49,50}, \mathrm{Mn}(\mathrm{IV})^{51}, \mathrm{Ni}(\mathrm{III})^{52}$ or $\mathrm{Ni}(\mathrm{I})^{53,54}$ metal ions show how the choice of ligand, electronic configuration of metal ion and the observed symmetry distortions all affect the magnetic relaxation and its mechanisms. The above systems are important contributions, nonetheless they are usually pretty unstable at room temperature, which would limit their potential applications. Copper(II) ion on the other hand forms very stable complexes and was demonstrated to be of interest for molecular magnetism studies. Notable examples of $d^{9} \mathrm{Cu}(\mathrm{II})$ systems were proposed to act as potential spin qubits with phthalocyanines ${ }^{55}$, 56, porphyrines ${ }^{46,57-59}$ acetylacetonates or dithiocatecholates ligating species. ${ }^{60-62}$ Recent record value of $1.4 \mathrm{~ms}$ coherence time was demonstrated by Dai et al. 60 for a $\left(\mathrm{PPh}_{4}\right)_{2}\left[\mathrm{Cu}(\mathrm{mnt})_{2}\right]$ (where $\mathrm{mnt}^{2-}$ is maleonitriledithiolate), after dilution in isostructural diamagnetic $\mathrm{Ni}(I I)$ matrix and utilization of dynamic decoupling technique. As for the SIM behavior, the examples of compounds with experimentally determined fieldinduced slow magnetic relaxation with single $d^{9} \mathrm{Cu}(\mathrm{II})$ ion are rather scarce ${ }^{63-67}$ and their origin is not fully understood. 42 , 43 This necessitates more studies within this class of compounds to gain deeper understanding of magneto-structural correlations and the underlying relaxation mechanisms.

Modular organic platforms that can be utilized for determination of magneto-structural correlations are difficult to construct, nonetheless they would be ideal for prediction of magnetic parameters based on the structural parameters alone. ${ }^{42}$ Herein, we present unique example of such system, which is suitable for construction of monometallic transition metal complexes, the structure of which can be carefully altered within the ascertained symmetry regime (Scheme 1 ).

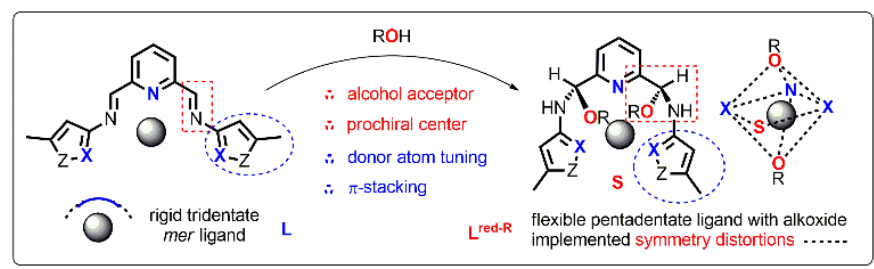

Scheme 1. Rationale behind the modular organic platform designed and implemented in the present studies for monometallic magneto-structural correlations.

The effect of the surrounding ligands and symmetry of the polyhedron on the static and dynamic magnetic properties of $\mathrm{Cu}(\mathrm{II})$ ions in these complexes is investigated. To rationalize our experimental results extensive computational studies are carried out utilizing SHAPE analysis, density functional theory (DFT)/ab initio and semiempirical approaches. This combined strategy enables to draw conclusions on magnetization relaxation mechanisms, magneto-structural correlations, the role of structural distortions, and usefulness of the proposed highly modular organic platform for designing new $\mathrm{Cu}(\mathrm{II})$ SIMs/qubits.

\section{Results and discussion}

\subsection{Synthesis}

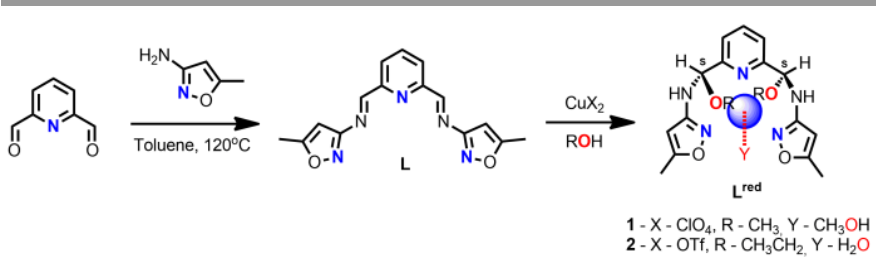

Scheme 2. Synthetic pathway leading to Schiff base ligand $\mathbf{L}$ and its copper(II) complexes; blue sphere represents $\mathrm{Cu}(\mathrm{II})$ ion.

Schiff base ligand $\mathbf{L}$ was synthesized via condensation of 2,6pyridinedicarboxaldehyde with 3-amino-5-methylisoxazole as presented in Scheme 2. Although $\mathbf{L}$ was isolated and characterized (see Section II in $\mathrm{SI}$ ), its complexation with $\mathrm{CuX}_{2}$ salts in the presence of alcohols leads to unexpected structural transformations. Reactions of $\mathrm{L}$ with $\mathrm{Cu}\left(\mathrm{ClO}_{4}\right)_{2} \cdot 6 \mathrm{H}_{2} \mathrm{O}(\mathbf{1})$ and $\mathrm{Cu}(\mathrm{OTf})_{2}$ (2) lead to the asymmetric addition of $\mathrm{MeOH}(1)$ or $\mathrm{EtOH}(2)$ to the imine bond, resulting in the formation of chiral $\mathrm{N}, \mathrm{O}$-aminal Lred-1/2, which is unambiguously established via $\mathrm{X}$ ray crystallography of isolated coordination compounds $\mathbf{1}$ and $\mathbf{2}$ (Table S1; Section 2.2). Whereas reduction of the parent ligand $\mathbf{L}$ is most plausibly facilitated by the template effect of $\mathrm{Cu}$ (II) ions, it is yet to be determined if such reaction is diastereospecific or one of the chiral isomers (here $S, S$ ) crystallized in the preferential manner. The solvent as well as the counter ions OTf- and $\mathrm{ClO}_{4}-$ does not seem to affect the type of the isomer obtained in both structures. Such chiral $\mathrm{N}, \mathrm{O}$ aminal motif is found in a number of natural, pharmaceutical products and valuable synthetic precursors ${ }^{68-70}$, therefore, the development of effective and effortless methods for their synthesis has attracted considerable research effort. ${ }^{71}$. 72 This report is the first on the formation of aldimine-derived $\mathrm{N}, \mathrm{O}$ aminals, without the need of applying the external chiral catalyst. Interestingly, only three studies ${ }^{71,73,74}$ on the use of metallic catalysts in the formation of $\mathrm{N}, \mathrm{O}$-aminals from related ketimines were reported. Altogether, our approach can be used to form chiral molecules with the $\mathrm{N}, \mathrm{O}$-aminals, strategically placed at the 2,6-positions of pyridine, of potential use in construction of more complex systems, particularly of biological or magnetic relevance.

\subsection{Structural characterization of $\mathrm{Cu}$ (II) complexes}

Figure $1 \mathrm{a}, \mathrm{b}$ shows the perspective views of molecules $\mathbf{1}$ (a) and 2 (b) together with the numbering schemes. Table S2 lists the relevant geometrical parameters. Pentadentate ligands $\mathbf{L}_{\text {red }}{ }^{1}$ $\left(\mathrm{ClO}_{4} ; \mathrm{MeOH}\right.$ )and $\mathrm{L}_{\text {red }}{ }^{2}$ (OTf-, EtOH) wrap around copper(II) ions and differ by either methoxy (1) or ethoxy (2) groups attached to the stereogenic center, as a result of the unexpected addition of alcohol to the imine bond (Scheme 2). 

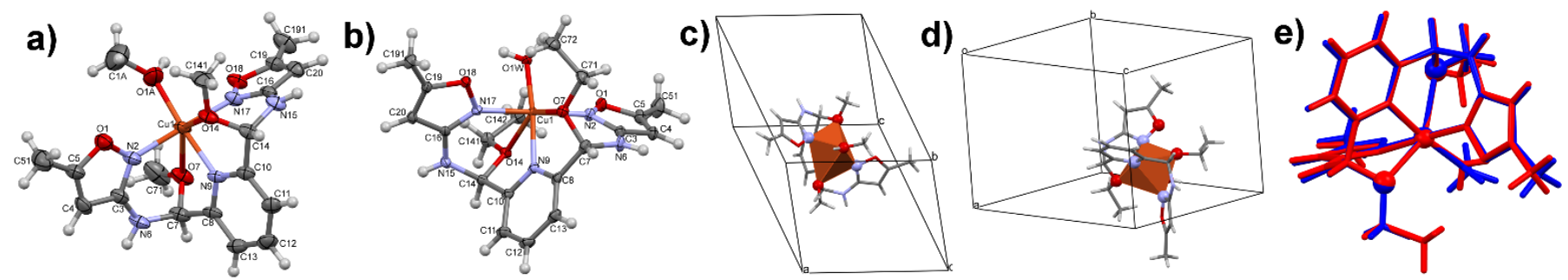

Figure 1. Perspective views of dicationic complexes $\mathbf{1}$ (a) and $\mathbf{2}$ (b). Ellipsoids are drawn at the $50 \%$ probability level, hydrogen atoms are shown as spheres of arbitrary units; The orientations of long axis of the coordination octahedron in $\mathbf{1}$ (c) and $\mathbf{2}$ (d); (e) Superimposed structures of dicationic complexes $\mathbf{1}$ (blue) and $\mathbf{2}$ (red).

In both crystal structures complexes exist as dications, with two perchlorate (1) or triflate (2) anions balancing the charge. $\mathrm{Cu}(\mathrm{II})$ centers are six-coordinated in distorted octahedral fashion (Figure 1c). Due to the structure of the ligand the octahedra are

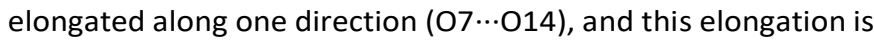
as large as $\mathbf{2 5 \%}$ in $\mathbf{1}$ and slightly smaller in $\mathbf{2}$ (Figure 1c,d). Such a geometry is related to the conformation of ligand molecules, in which the ring planes are almost perpendicular one to another (Table S2). This also results in a nearly square tetradentate plane formed by three nitrogen atoms of the $\mathbf{L}^{\text {red- }}$ $1 / 2$ ligand and the oxygen atom from the solvent molecule (see SHAPE analysis in Section 2.3). In the crystal structure of 1 there are infinite chains of alternate cations and anions connected by the hydrogen bonds, with the second anion threaded to this chain (Figure S1 (left), (Table S3). In 2, the main structural motif is a cluster of hydrogen bonded structural fragments: two cations, four triflate anions, and two solvent-ethanol molecules (Figure S1 (right)). These principal motifs are connected to form the three-dimensional crystal structure by means of electrostatic interactions and weak intermolecular van der Waals forces. Different $\mathrm{H}$-bonding patterns are also responsible for changes in the electronic dipole character of the coordinated solvent molecule ( $\mathrm{MeOH}$ in 1 and $\mathrm{H}_{2} \mathrm{O}$ in 2) which can theoreticaly affect the magnetic properties as well.

\subsection{SHAPE analysis and symmetry considerations}

To gain more insight into the local site-symmetry in $\mathbf{1}$ and $\mathbf{2}$, calculations using SHAPE software ${ }^{75,76}$ were performed, which utilize the continuous shape measurements (CShM) $)^{77}$ method. $S$ parameter is therefore introduced, which corresponds to the degree of deviations from the perfect polyhedron with $S=0$ corresponding to ideal geometry. Results shown in Table S4 clearly indicate that $\mathbf{1}$ and $\mathbf{2}$, as well as magnetically relevant $\mathrm{Cu}(\mathrm{II})$ system studied by Boca ${ }^{63}$ show significant deviations from the octahedral geometry, classified as structurally severe distortions $(\mathrm{S}>3) .{ }^{75}$ Considering that observation of slow magnetic relaxation in $\mathrm{Cu}$ (II) systems should be related to the deviations from idealized symmetry, one can speculate and relate the differences in S-value to slower (1) or faster (2) relaxation of magnetization (see $A C$ studies in Section 2.5). Although it is not very high (ca. 0.2 ), the chemically significant differences were classified to be visible from 0.1 value changes. ${ }^{75}$ Though more examples of octahedral $\mathrm{Cu}(\mathrm{II})$ ions that exhibit slow relaxation of magnetization would have to be studied beforehand, we hypothesize that based on Table S4, octahedral distortions characterized by $\mathrm{S}$-value $=$ ca. 3.7 value might be the limiting factor when the onset of the magnetic relaxation is observed. This would mean that for isolated $\mathrm{Cu}$ (II) ions in an octahedral $\mathrm{m}$ environment, any distortions smaller than that would result in lack of this magnetic phenomenon.

Given that investigated systems are heterotopic in terms of ligands nature ( $\mathrm{N}$ and $\mathrm{O}$ donor atoms), we performed additional analysis regarding square planar planes present in the studied octahedra. The aim was to understand: (i) which part of the ligands architecture is responsible for structural anisotropy of relevance to magnetic properties and (ii) why do the observed magnetic properties differ in $\mathbf{1}$ and $\mathbf{2}$. Results are gathered in Table S5. One can discriminate three planes: (A) (N2-N9-N17$\mathrm{MeOH} / \mathrm{H}_{2} \mathrm{O}$ ) which is dependent on the monodentate $\mathrm{MeOH}(\mathbf{1})$ or $\mathrm{H}_{2} \mathrm{O}(2)$ solvent molecules; (B) $\left(\mathrm{MeOH} / \mathrm{H}_{2} \mathrm{O}-\mathrm{N} 9-07-014\right)$ and (C) (N2-N17-O7-O14) which are mostly affected by the 07-O14, distortions. Unexpectedly, it appears that plane (A) alone would favor a significantly larger distortions in compound $\mathbf{2}$ (S-value $\mathbf{2}$ $=0.308$ vs S-value $1=0.077$ ). This should also dependent on the $\mathrm{H}$-bonding pattern with the perchlorate (1) or triflate (2) counterions. S-values in planes (B) and (C) favour stronger distortions in $\mathbf{1}$ than in 2, ascribed to the plane formed by isoxazole/alkoxide moieties.

From the structural point of view, we hypothesize that the difference in the magnetic properties of $\mathbf{1}$ and $\mathbf{2}$ are related to: (i) the reduced octahedral distortions in $\mathbf{2}$ when compared to $\mathbf{1}$ as well as (ii) larger deviation from the square planar character within the N3O plane for $\mathbf{2}$ than in $\mathbf{1}$. Interestingly, although the monodentate coordination of $\mathrm{H}_{2} \mathrm{O}$ results in larger deviation from the $\mathrm{NNN}^{-\mathrm{OH}_{2}}$ plane in $\mathbf{2}$ than chemically equivalent $\mathrm{NNN}$ $(\mathrm{OH}) \mathrm{Me}$ in $\mathbf{1}$, this effect seems to be more profound than distortions in the planes (B) and (C) associated with coordinating methoxy/ethoxy moieties of the reduced ligand. This can be understood when considering that the spin-active nitrogen atoms have the negative effect on the SIM/qubit behaviour 46,47 , which is however minimized within the square planar coordination environment. 

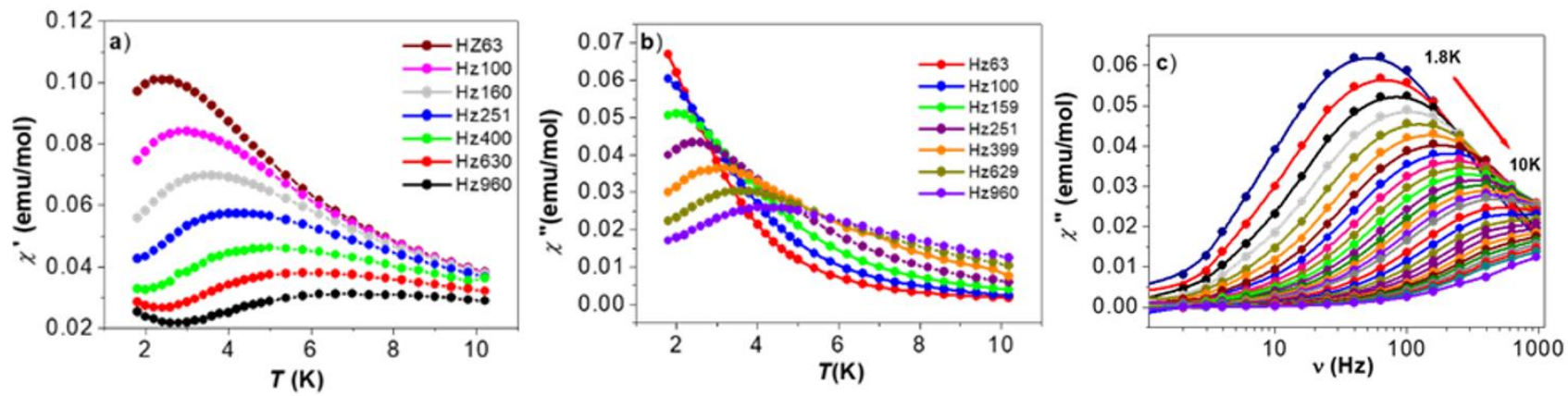

Figure 2. Temperature dependence of: a) the in-phase $\chi^{\prime}$, b) the out-of-phase $\chi^{\prime \prime}$ susceptibility and c) $\chi^{\prime \prime}$ vs frequency for compound 1

\subsection{DC magnetic properties}

The magnetic properties of powdered microcrystalline samples $\mathbf{1}$ and $\mathbf{2}$ were studied by measuring the thermal dependence of the magnetic susceptibility in the temperature range of 1.8 $300 \mathrm{~K}$ and magnetic field of $0.5 \mathrm{~T}$. The field dependences of the magnetization from 0 to $5 \mathrm{~T}$ for 1 and $\mathbf{2}$ were measured at $2 \mathrm{~K}$. In DC magnetic field both compounds show similar properties, typical for non-interacting $S=1 / 2$ spin system (Figure S2). The $\chi_{\mathrm{m}} T$ product values $\left(0.373 \pm 0.005 \mathrm{~cm}^{3} \mathrm{Kmol}^{-1}, \mu_{\text {eff }}=1.73 \pm 0.01\right.$ B.M.) are practically constant in the whole measured temperature range $1.8-300 \mathrm{~K}$. The $1 / \chi_{\mathrm{m}}$ versus $T$ plots obeys the Curie-Weiss law with Curie constant $\mathrm{C}=0.384$ and $0.393 \mathrm{~cm}^{3} \mathrm{Kmol}^{-1}$ and Weiss constant $\theta=-0.1$ and $-0.3 \mathrm{~K}$ for 1 and 2 , respectively. Simulation of magnetic susceptibility curves using molecular field correction: ${ }^{78,79}$

$$
\chi_{m}=\frac{\chi}{\left(\frac{2 z J^{\prime}}{N g^{2} \beta^{2}}\right) \chi}
$$

incorporated in the $\mathrm{PHI}$ program ${ }^{80}$ yields very low parameters: $\mathrm{zJ}=-0.05$ and $-0.10 \mathrm{~cm}^{-1}$ for $\mathbf{1}$ and $\mathbf{2}$, respectively. The goodness of agreement factor $\mathrm{R}$, defined as:

$$
R=\sum_{i=1}^{n} \frac{\left(\chi_{i}^{\exp } T-\chi_{i}^{\text {calc }} T\right)^{2}}{\left(\chi_{i}^{\exp } T\right)^{2}}
$$

was obtained as: $R=4.43 \cdot 10^{-6}$ and $2.02 \cdot 10^{-6}$ for $\mathbf{1}$ and $\mathbf{2}$, respectively. This finding confirms that $\mathrm{Cu}(\mathrm{II})$ centers are practically magnetically isolated in both compounds, in accordance with determined X-ray structures (see Section 2.2). Hence the effect of exchange coupling between $\mathrm{Cu}(\mathrm{II})$ ions may be excluded. Magnetically isolated $\mathrm{Cu}(\mathrm{II})$ ions in the crystal structure of $\mathbf{1}$ and $\mathbf{2}$ are also confirmed by magnetization versus field measurements measured at $2 \mathrm{~K}$ (Figure S3). Experimental points agree with the Brillouin function for $S=1 / 2$ and $g=2$.

\subsection{AC magnetic properties}

Measurements were made at $3 \cdot 10^{-4} \mathrm{~T}$ oscillating field for 16 frequencies, in the temperature range $1.8-10 \mathrm{~K}$. An external magnetic DC field of $0.1 \mathrm{~T}$ was chosen from the maximum of out of phase susceptibility $\chi^{\prime \prime}$ versus magnetic field relation (Figures S4 and S5). Please notice that much stronger field must be applied for compound $\mathbf{2}$ than for $\mathbf{1}$, which also correlates with more pronounced character of slow magnetic relaxation in AC field for the latter one (vide infra). The AC susceptibility measurements reveal surprising finding. The out of phase component $\chi^{\prime \prime}$ of $\mathbf{1}$ and $\mathbf{2}$ is silent at zero DC field, which indicates that the magnetization relaxation time $(\tau)$ is much shorter than $1 / 2 \pi v$ of the AC field. Measurements done under 0.1 T Dc field reveal differences in properties of compounds 1 and 2. The in-phase $\chi^{\prime}$ (Figure 2a) and out-of-phase $\chi^{\prime \prime}$ (Figures 2b,c) susceptibilities show temperature and frequency dependence with characteristic maxima in $\mathbf{1}$, indicating the slow magnetic relaxation phenomenon. Different types of relaxation mechanisms can be potentially involved in molecular system: Orbach, direct, Raman, and quantum tunneling (QTM) components, respectively). ${ }^{63,64}$

$$
\tau^{-1}=\tau_{0}^{-1} \exp \left(-\frac{U}{k_{B} T}\right)+a T+b T^{n}+\tau_{Q T M}^{-1}
$$

In the literature, one can find different approaches to the Arrhenius equation:

$$
\tau^{-1}=\tau_{0}^{-1} \exp \left(-\frac{U}{k_{B} T}\right)
$$

performed in AC magnetic field studies for the relaxation processes observed for coordination compounds with spin $S=$ $1 / 2$. Some authors suggest that $\tau$ does not follow the Arrhenius behavior, because of lack of magnetic states besides $m_{S}= \pm 1 / 2$ doublet that can be thermally populated providing a path for the multiphonon Orbach mechanism of relaxation. Consequently, they propose to use Raman and direct mechanisms, which dominate at high and low temperature respectively. ${ }^{44,81,82}$ Other authors, such as Boca et al ${ }^{63}$, use Arrhenius-like plot to determine activation energy of the relaxation process $\mathrm{U} / \mathrm{k}_{\mathrm{B}}$ and $\tau_{0}$, admitting that effective energy barrier from zero-field splitting of the ground term does not exist in the $\mathrm{Cu}(\mathrm{II})$ system. It results in elimination of the Orbach 
Table 1 Fitting of different relaxation parameters of compound 1 determined from AC studies based on Figure $3 a$.

\begin{tabular}{|l|l|l|l|l|l|}
\hline $\begin{array}{l}\text { Relaxation } \\
\text { mechanism }\end{array}$ & $\mathbf{b}\left(\mathbf{s}^{-1} \mathbf{K}^{-\mathbf{n}}\right)$ & $\mathbf{n}$ & $\mathbf{a}\left(\mathbf{s}^{-1} \mathbf{K}^{-1}\right)$ & $\mathbf{\tau}$ QTM $\left(\mathbf{s}^{-1}\right)$ & $\begin{array}{l}\text { Discrepancy } \\
\text { factor } \mathbf{R}\end{array}$ \\
\hline Raman+direct+QTM & $18.59(2)$ & $1.32(1)$ & $1.06(2)$ & $0.46(2)$ & $4.05 \cdot 10^{-5}$ \\
\hline Raman+direct & $18.78(1)$ & $1.33(2)$ & $3.66(2)$ & & $4.05 \cdot 10^{-5}$ \\
\hline Raman & $68.76(1)$ & 2.32 & & & \\
\hline
\end{tabular}
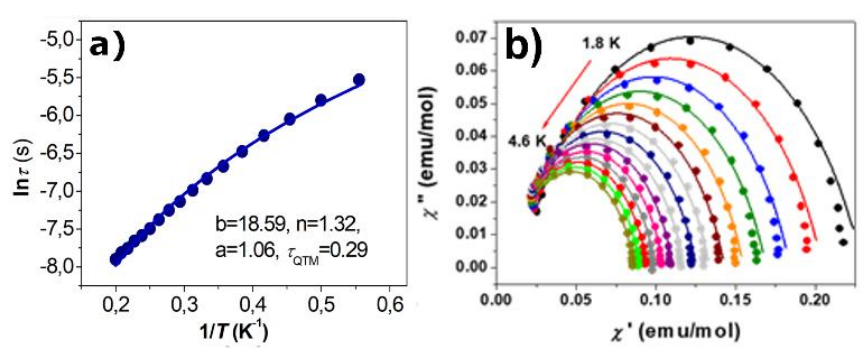

Figure 3. (a) Magnetization relaxation time $\ln (\tau)$ in a function of reciprocal temperature $\mathrm{T}^{-1}$ of 1. The effect of using Raman + direct + QTM in fitting procedure is presented in the form of a continuous line; (b) Cole-Cole plots for 1 under $0.15 \mathrm{~T}$ dc field. The solid lines are the best fits to the experiments with the generalized Debye model. ${ }^{64}$

mechanism in relaxation process in $S=1 / 2$ compounds. The analysis of the relaxation process of $\mathbf{1}$ was carried out using: a) the Raman mechanism itself; b) Raman and direct processes; c) Raman, direct and QTM relaxation modes, knowing that Raman mechanism plays a dominant role in $S=1 / 2$ system. ${ }^{81}$ The $\tau^{-1}$ vs $T$ dependence is almost linear, what suggests that direct relaxation mechanism cannot be ignored. ${ }^{81}$ The matching results of fitting are shown in the Table 1 and in Figure 3a. Accounting only the Raman mechanism gives a good fit but too high a value of $b=68.76$. Calculation with Raman and direct mechanisms as well as Raman, direct and QTM gave parameters $\mathrm{b}=18.59 \mathrm{~s}^{-1} \mathrm{~K}^{-1.32}, \mathrm{n}=1.32$, $\mathrm{a}=1.06$ and QTM equal 0.46 , similar to those found for $S=1 / 2$ spins in Cu(II) complexes. ${ }^{64}$ Authors of 64 finally proposed Raman-like process is operative in spinlattice relaxation in analyzed five coordinated $\mathrm{Cu}$ (II) complex. In the Raman process, relaxation follows through a virtual state. The direct process describes relaxation from $-1 / 2$ to $+1 / 2$ states with emission of a single lattice phonon. Relaxation through QTM is facilitated by the anisotropy of the system. ${ }^{54}$

The Cole-Cole plots from the AC magnetic susceptibility data of 1 (Figure $3 b$ ) were fitted by the generalized Debye model (Table S6). ${ }^{83,} 84$ The $\alpha$ parameters describing the distribution of the relaxation times in a magnetic system were extracted. The limiting value of $\alpha=0$ describes a single relaxation process, whereas $\alpha=1$ corresponds to an infinitely wide distribution of the relaxation times. The wider the distribution of the relaxation times, the larger the value of $\alpha .{ }^{83,87}$ A small value of the distribution coefficient $\alpha(0.16$ at $4.4 \mathrm{~K}$ to 0.25 at $1.8 \mathrm{~K}$ ) for complex 1 indicates that the relaxation process has a narrow distribution of relaxation time. The $\tau$ parameters were extracted from the Debay model (Figure S6), with $\tau=3.97$ $\mathrm{ms}$ at 1.8.K. Similar temperature relations and values were presented for vanadium(IV)-based compounds, with $S=1 / 2.85$

AC susceptibility measurements of compound $\mathbf{2}$ differ from 1, with no phase shift maxima present in the in-phase $\chi^{\prime}$ vs T dependencies (Figure 4a) and only the slight onset of the outof-phase signals $\chi^{\prime \prime}$ vs T (Figures $4 b$ and c) under high external magnetic field frequencies. Despite high structural resemblance of the $\mathrm{CU}$ (II) coordination environment, the properties of $\mathbf{1}$ and 2 differ significantly and this precluded us from determination of the relaxation parameters for the latter compound. Boča et al. ${ }^{63}$ showed that octahedral $\left[\mathrm{Cu}(\right.$ pydca) $(\mathrm{dmpy})] \cdot 0.5 \mathrm{H}_{2} \mathrm{O}$ (where pydca - pyridine-2,6-dicarboxylate, dmpy - 2,6dimethanolpyridine) exhibits two relaxation processes with energy barriers estimated as $\mathrm{U} / \mathrm{k}_{B}=58.6$ and $62.7 \mathrm{~K}$ (possibly as a result of two distinct, symmetry differentiated $\mathrm{Cu}(\mathrm{II})$ in the crystal lattice). Cui et al. ${ }^{64}$ showed that five-coordinate $[\mathrm{Cu}(12-$ $\mathrm{TMC}) \mathrm{Cl}]\left[\mathrm{B}\left(\mathrm{C}_{6} \mathrm{H}_{5}\right)_{4}\right] \quad(12-\mathrm{TMC}=$ 1,4,7,10-tetramethyl-1,4,7,10tetraazacyclododecane) exhibits only one relaxation process in a distorted square pyramidal geometry of copper(II) ion. Korchagin et al. demonstrated that the quasi-one-dimensional $\mathrm{Cu}(\mathrm{II})$ complex $\left[\mathrm{Cu}(\mathrm{hfac})_{2}(\mathrm{ClTDPO})\right]_{n}$ (where hfac hexafluoroacetylacetonate, CITDPO - 2,4-di-(tert-butyl)-9chloro-benzo[5,6][1,4]oxazine[2,3- $b]$ phenoxazine) relaxes through the combination of two-phonon Raman and onephonon direct processes. ${ }^{67}$

\subsection{CW-EPR and pulsed EPR studies}

Continuous wave electron paramagnetic resonance (CW-EPR) spectra were recorded in $\mathrm{X}$ and $\mathrm{Q}$ band frequencies to corroborate magnetic phenomena (Sections 2.4 and 2.5) with structural studies (Sections 2.2 and 2.3), whereas the pulsed variant of the method allowed to better understand the spinlattice magnetic relaxation processes. For experimental details see EPR Section III in the SI. CW-EPR spectra of compounds 1 and $\mathbf{2}$ in liquid nitrogen ( $\mathrm{X}$-band) and helium ( $\mathrm{Q}$-band) temperatures with fitting protocols are shown in the SI (Figures S7-S16) with representative ones in Figure 5. The spectroscopic splitting factors $g_{\perp}$ and $g_{\|}$for all spectra are presented in Table 2 and prove their axial character type $\left(g_{\|}>g_{\perp}\right)$.
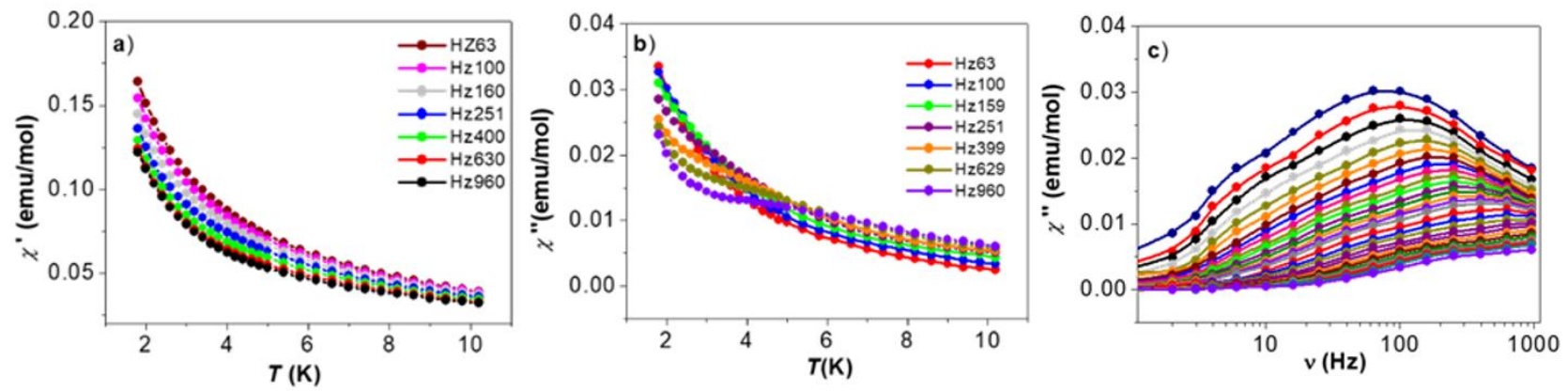

Figure 4. Temperature dependence of: a) the in-phase $\chi^{\prime}$, b) the out-of-phase $\chi^{\prime \prime}$ susceptibility and $\chi^{\prime \prime}$ vs frequency dependence of the compound $\mathbf{2}$ 
Transition energy levels at the resonance field $B_{\text {res }}$ are presented in Tables S7 and S8 and their graphical representation in Figures S17 and S18. Room temperature Xband EPR spectra of $\mathbf{1}$ and $\mathbf{2}$ (Figure 5 top) are temperatureindependent down to 77K. For 1 the axial type spectrum spectrum is partially, but clearly resolved with spectroscopic splitting factors $g_{\perp}=2.06, g_{\|}=2.28$ and parallel hyperfine splitting parameter $A_{\|}=175 \mathrm{G}$, resulting from the interaction of the unpaired electron of $\mathrm{Cu}(\mathrm{II})$ with the spin of copper nucleus I $=3 / 2$. It is identical for both natural isotopes of ${ }^{63} \mathrm{Cu}$ and ${ }^{65} \mathrm{Cu}$, so eight hyperfine levels can be expected with four allowed transitions: $\Delta M_{s}= \pm 1$ and $\Delta M_{1}=0$ (Figure S19)..$^{86}$ The axial EPR spectrum of compound $\mathbf{2}$ exhibits similar values of spectroscopic splitting parameters $g_{\perp}=2.06$ and $g_{\|}=2.25$ but with no hyperfine structure. From spectra in Q-band valuable information can be obtained, because the hyperfine structures are more pronounced for both compounds
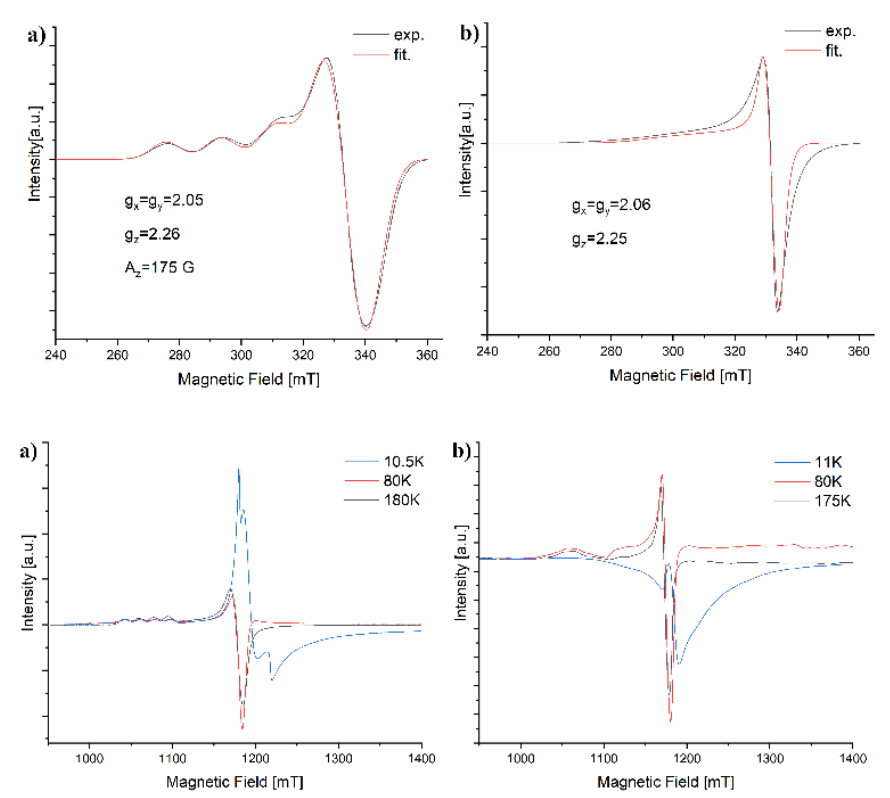

Figure 5. Top: X-band EPR spectra of $\mathbf{1}$ (a) and $\mathbf{2}$ (b) at RT; solid red line shows temperature independent simulated spectrum with parameters presented. The sam type of spectrum with the same parameters were observed at $77 \mathrm{~K}$; bottom superposition of Q-band spectra of $\mathbf{1}$ (a) and $\mathbf{2}$ (b) at chosen temperature intervals: representative simulated spectra are shown in the SI.

Table 2. The fitted SH parameters: Zeeman factors ( $g_{i}$; dimensionless), hyperfine interaction $\left(A_{i} ;\right.$ in $\left.10^{-4} \mathrm{~cm}^{-1}\right)$ and spectral parameters for compounds $\mathbf{1}$ and $\mathbf{2}$.

\begin{tabular}{|c|c|c|c|c|c|c|c|c|}
\hline Cmpd & \multicolumn{4}{|c|}{1} & \multicolumn{4}{|c|}{2} \\
\hline $\begin{array}{c}\text { EPR } \\
\text { band }\end{array}$ & $x$ & Q & $x$ & $\mathrm{Q}$ & $x$ & Q & $x$ & Q \\
\hline $\mathrm{T}[\mathrm{K}]$ & 300 & 180 & 90 & 10.5 & 300 & 300 & 91 & 11 \\
\hline$g_{1}$ & 2.029 & 2.048 & 2.035 & 1.950 & 2.059 & 2.053 & 2.060 & 2.012 \\
\hline$g_{2}$ & 2.071 & 2.040 & 2.063 & 2.029 & 2.059 & 2.053 & 2.062 & 2.067 \\
\hline$g_{3}$ & 2.259 & 2.258 & 2.258 & 2.289 & 2.32 & 2.307 & 2.185 & 2.349 \\
\hline$\left[g_{3}-g_{1}\right]$ & 0.230 & 0.210 & 0.223 & 0.339 & 0.261 & 0.254 & 0.125 & 0.337 \\
\hline$A_{1}$ & -4.79 & 2.739 & -3.33 & 23.34 & -1.756 & -0.0002 & 0.0002 & 36.69 \\
\hline$A_{2}$ & -0.37 & $\begin{array}{c}- \\
25.47\end{array}$ & $\begin{array}{c}3.2 \mathrm{E}- \\
05\end{array}$ & $\begin{array}{c}- \\
0.116\end{array}$ & -0.232 & 0.0034 & 0.0002 & $\begin{array}{c}- \\
60.04\end{array}$ \\
\hline$A_{3}$ & 179.73 & 184.5 & 187.52 & 206.8 & 128.7 & 141.7 & 102.80 & 240.2 \\
\hline
\end{tabular}

\begin{tabular}{|c|c|c|c|c|c|c|c|c|}
\hline $\begin{array}{c}\text { Lwpp } \\
\text { [mT] }\end{array}$ & 10.022 & 12.21 & 10.98 & 15.98 & 6.35 & 8.95 & 6.39 & 18 \\
\hline RMSD* $^{*}$ & 0.005 & 0.011 & 0.010 & 0.056 & 0.031 & 0.032 & 0.028 & 0.11 \\
\hline
\end{tabular}

and it can be also observed for compound 2, which was not the case for X-band frequencies. Down in helium temperatures, formation of a bimodal peak is observed for compound 1 in the range of 1200-1300 $\mathrm{mT}$ magnetic field. The second line is and image of transitions in the perpendicular direction (i.e. $x y \| B$ ), this effect is clearly observed for sample $\mathbf{1}$, while for sample $\mathbf{2}$ it is less apparent due to larger line widths. This phenomenon is even more visible in temperature-dependent EPR spectra (Figures S7 and S8) which can be attributed to different orientations of molecules in crystal lattice relative to the magnetic field but would also depend on the structure of individual compounds. In addition, the LFMA (Low Field Microwave Absorption) line, which is an indicator of ferromagnetic interactions, does not occur even up to helium temperatures for both tested samples. This means ferromagnetic interactions are not present in $\mathbf{1}$ and $\mathbf{2}$, which is consistent with the DC susceptibility studies (see Section 2.4).

In the systems where the $D$ parameter cannot be assigned $(S=$ $1 / 2)$ it is possible to predict the presence of magnetic anisotropy based on the $\left[g_{z}-g_{x}\right]$ difference. ${ }^{63}$ The values (Table 2 ) for $\mathbf{1}$ and $\mathbf{2}$ are three times higher than for the related system presented in the literature, which indicates that it can be exploited in quantifying the magnetic anisotropy. Nevertheless, since at liquid helium temperatures $\left[g_{\mathrm{z}}-g_{\mathrm{x}}\right]$ values are similar for $\mathbf{1}$ and $\mathbf{2}$, it is not the only parameter that should be considered to explain the magnetic behavior (with magnetic relaxation being much longer for $\mathbf{1}$ than in 2). One can also observe that temperature significantly affects the $g_{\text {eff }}$ factor (Figure S20) and the EPR line width $B_{p p}$ (Figure S21) for both compounds down to the liquid helium temperatures.

The in-depth structural analysis for both compounds shows that although they are sufficiently separated to exclude coupling for 1 there are two opposite centers exactly inverted and the pairs are perfectly parallel. For $\mathbf{2}$ they are also inverted, but the pairs are not parallel (Figure S22). Additionally, position of pyridine rings in $\mathbf{1}$ is very similar to those presented in the publication ${ }^{87}$, while for $\mathbf{2}$ their somewhat equivalent role is taken by the five-membered oxazole rings. These structural differences can also contribute to the differences in the observed EPR spectra between 1 and 2. SHAPE analysis (see Section 2.3) also shows that for 1 the deviations for the plane N2-N9-N17-MeOH from the perfectly square planar disposition are significantly smaller than in compound $\mathbf{2}$, which is most preferred for QIP systems. ${ }^{46,47}$

To gain insight into relaxation processes of the compounds, we performed the pulsed EPR spectra in Q-band down to liquid helium temperatures. The relaxation time $T_{1}$ determined for both compounds are presented in Figures S23 and S24. For compound 1 , the $T_{1}$ increase very fast in range of $28-34 \mathrm{~K}$, but similar behavior is observed in different $S=1 / 2$ systems. ${ }^{61,88}$ For 2 the behavior is different and we observe a shortening of $T_{1}$ with 
increasing temperature. The inverse spin-lattice relaxation $\left(1 / T_{1}\right)$ model (Figure S25 and EPR Section III in SI) allowed us to assign two processes (Raman and direct) having the greatest impact on relaxation, what correlates well with the $A C$ magnetic susceptibility studies (Section 2.5).

\subsection{Theoretical calculations of spin Hamiltonian parameters}

Using PHI program ${ }^{80}$ we simulated EPR spectra and variation of electronic levels with external magnetic field for compound 1. To simulate $\mathrm{Cu}(\mathrm{II})$ ion we set spin $S$ as $1 / 2$ and orbital quantum number $L$ as 2. Spin Hamiltonians (SH) parameters (Section 2.9) were calculated using MOLCAS ${ }^{89}$ and we take $g_{\mathrm{x}}=2.0660, g_{\mathrm{y}}=$ 2.0920, $g_{z}=2.3810$ from NEVPT2 calculations (Section 2.9). Temperature was set at $300 \mathrm{~K}$, field frequency at $10 \mathrm{GHz}(\mathrm{X}$ band), field was swept from 0.25 to 0.4 Tesla and was directed along the $\mathrm{x}_{-}, \mathrm{y}^{-}$, and $\mathrm{z}$-axis of $\mathrm{g}$-tensor as well as powder integration was used. We used anisotropic spectra line widths to get better resemblance to experimental fits. Observed anisotropic broadening (Figures S26, S27) might correspond to unresolved spectral features such as hyperfine coupling 90,91 and correlates with the experimentally observed structures.

\subsection{Optical spectroscopy}

To gain more insight into the electronic levels of 1 and therefore the nature of observed slow magnetic relaxation, optical spectroscopy and superposition model (SPM) calculations (Section 2.10) were performed.
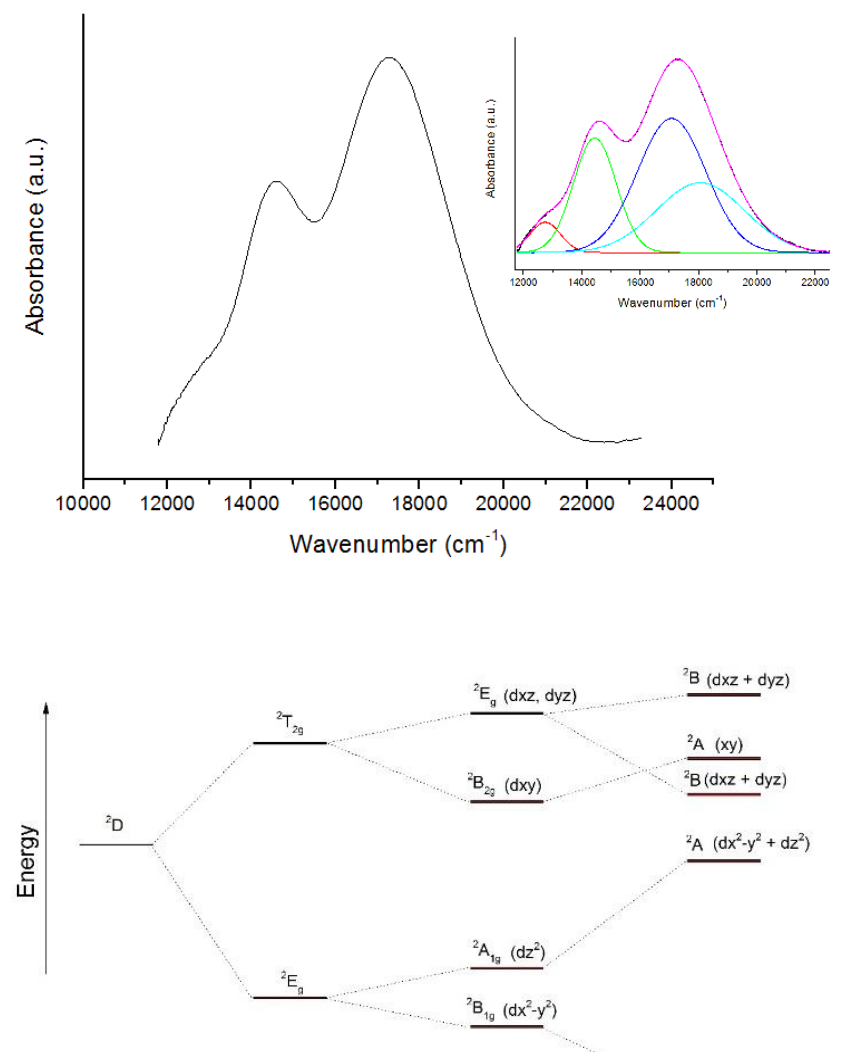

Figure 6. (Top) Absorption spectrum of $\mathbf{1}$ in the range of $\mathrm{Cu}$ (II) electronic transitions at $4.2 \mathrm{~K}$; (bottom) Energy level diagrams for $\mathrm{Cu}(\mathrm{II})$ ion as a function of symmetry changes.

Figure S28 shows the absorption spectrum measured at RT for complex 1 . The intense bands observed in the range of 22,000 $50,000 \mathrm{~cm}^{-1}$ are associated with ligand-centered transitions. Electronic transitions of $\mathrm{Cu}$ (II) ions are much less intense than those associated with ligand absorption. They appear clearly for a more concentrated sample (blue line) and are observed in the range of $12,000-21,000 \mathrm{~cm}^{-1}$. Figure 6top shows the absorption spectrum recorded in the range of $\mathrm{Cu}(\mathrm{II})$ electronic transitions at $4.2 \mathrm{~K}$. Two bands at approximately 14,600 and $17,300 \mathrm{~cm}^{-1}$ and a shoulder at approximately $12,600 \mathrm{~cm}^{-1}$ are clearly visible. Based on the above reasoning (details are in Section IV in SI) and the results of ab initio calculations (Section 2.9) the following energy level sequence can be proposed for $\mathrm{Cu}(\mathrm{II})$ in 1 assuming approximate $\mathrm{C}_{2}$ symmetry: ${ }^{2} \mathrm{~A}_{2}\left(d \mathrm{x}^{2}-\mathrm{y}^{2}+d \mathrm{z}^{2}\right)$ $<{ }^{2} \mathrm{~A}\left(d \mathrm{z}^{2}+d \mathrm{x}^{2}-\mathrm{y}^{2}\right)<{ }^{2} \mathrm{~A}(d \mathrm{xy})<{ }^{2} \mathrm{~B}(d \mathrm{xz}+d \mathrm{y}, \mathrm{z})<{ }^{2} \mathrm{~B}(d \mathrm{xz}+d \mathrm{y}, \mathrm{z})$ (Figure 6bottom). Accordingly, to the proposed energy levels structure four bands are expected in absorption spectrum of 1 . Deconvolution of the experimental spectrum using four Gaussian functions is presented in the inset in Figure 6top. The obtained bands with maxima at 12743, 14441, 17073 and 18056 $\mathrm{cm}^{-1}$ correspond to transitions from the ground ${ }^{2} \mathrm{~A}_{2}\left(d \mathrm{x}^{2}-\mathrm{y}^{2}+d \mathrm{z}^{2}\right)$ level to the ${ }^{2} \mathrm{~A}\left(d \mathrm{z}^{2}+d \mathrm{x}^{2}-\mathrm{y}^{2}\right),{ }^{2} \mathrm{~B}(d \mathrm{xz}+d \mathrm{y}, \mathrm{z}),{ }^{2} \mathrm{~B}(d \mathrm{xz}+d \mathrm{y}, \mathrm{z})$ and ${ }^{2} \mathrm{~A}(d \mathrm{xy})$ excited levels. The value of $D q$ in the $\mathrm{O}_{\mathrm{h}}$ approximation can be estimated as the difference between the average energy of levels arising from $\mathrm{T}_{2 g}\left(\mathrm{O}_{h}\right)$ and $\mathrm{E}_{g}\left(\mathrm{O}_{h}\right)$ states. This yields a value of $D q \sim 1015 \mathrm{~cm}^{-1}$, which seems to be reasonably acceptable. For compound $\mathbf{2}$ the RT absorption spectrum is practically the same as for compound 1 (Figure S31). Therefore, for the purpose of present analysis we accepted the same energy level structure for compounds $\mathbf{1}$ and $\mathbf{2}$. The determined limiting values of $D q$, i.e. 1015 and $1285 \mathrm{~cm}^{-1}$ were used in SPM analysis (Section 2.10).

\section{9 (TD)DFT and CASSCF $a b$ initio approaches}

\subsubsection{DFT ground state calculations}

B3LYP solutions of total spin $S=1 / 2$ of $\mathrm{Cu}$ (II) ions of relevance to the magnetic properties were determined. Table S10 in SI lists Mulliken populations for $\mathrm{Cu}$ atom and neighboring $\mathrm{N}$ and $\mathrm{O}$ atoms based on X-ray structures of compounds $\mathbf{1}$ and $\mathbf{2}$. The results show localization of charge and spin of $\mathrm{Cu} 3 d$ electrons and support modelling of compounds with pseudospin Hamiltonian ${ }^{92}$ with value of spin equal to $S=1 / 2$ (Sections IV and $\mathrm{V}$ in $\mathrm{SI}$ ). Results of Mulliken analysis show that on $3 d$ orbitals there are 9.295 electrons, close to nominal value of 9 . Spin for $3 d$ shell is equal to 0.691 , leaking mainly to $\mathrm{N}$ atoms. Expectation value of operator of total $\mathrm{S}^{2}$ is equal to 0.7521 , close to ideal value of 0.75 . Neighboring $\mathrm{O}$ atoms are more electrically polarized than nitrogen atoms suggesting more ionic bonds, which is also supported by Loewdin and Mayer analysis ${ }^{93}$ (Table $\mathrm{S} 11)$. The $\mathrm{N}$ atoms are more spin polarized than $\mathrm{O}$ atoms, suggesting that $\mathrm{Cu}-\mathrm{N}$ are more covalent bonds. Comparison of charges on $\mathrm{N}$ and $\mathrm{O}$ atoms between compounds $\mathbf{1}$ and $\mathbf{2}$ also allows us to understand how they translate to the magnetic properties. Charges on the chemically equivalent $\mathrm{N}$ atoms are 
essentially the same for $\mathbf{1}$ and $\mathbf{2}$, whereas main differences arise from the $\mathrm{O}$ atoms. $\mathrm{O} 7$ and $\mathrm{O} 14$ atoms are responsible for the structural distortions (Sections 2.3 and 2.10) and slightly lower charges in $\mathbf{1}$ than in $\mathbf{2}$. The biggest difference in charge comes from the coordinated solvent molecules, with $\mathrm{MeOH}$ (1) translating to lower charge than $\mathrm{H}_{2} \mathrm{O}(2)$. This comes from the inherent basicity of the molecule per se, but also from the $\mathrm{H}$ bonding pattern that differs within the synthesized systems (Section 2.2). Interestingly, for experimental structure of compound $\mathbf{2}$ it was not possible to get the magnetic solution with spin localized at the $\mathrm{Cu}$ center. $\mathrm{Cu}$ atom is nonmagnetized with small leakage of charge $(+0.3863|\mathrm{e}|)$. This corresponds more closely to $S=0$ and $\mathrm{Cu}(\mathrm{I})$ oxidation state than to $\mathrm{Cu}(\mathrm{II} ; \mathrm{S}=$ $1 / 2$ ). Only after optimization of geometric structure we obtained magnetic state with localized magnetic moment but during the process of geometry optimization the bond between $\mathrm{Cu}$ and $\mathrm{H}_{2} \mathrm{O}$ is broken and coordination number changes from 6 to 5 . This suggest that there might be close-lying energetic states with different valence properties and geometrical structures. Our computations reveal that the reason for the differences in the properties of both compounds $\mathbf{1}$ and $\mathbf{2}$ is not solely related to the immediate surroundings of the $\mathrm{Cu}$ ions, but with other factors as well. For test computations we have considered variations due to bound water or methanol. Preliminary results show however that it is not the case. Other factors, e.g. changes in valence and ionicity with counterions, may be considered as hypothesis in a future study.

\subsubsection{TDDFT excited state calculations}

Excited states were computed for compound 1 using TDDFT with long-range corrected exchange-correlation functional CAM-B3LYP. Energies of standard B3LYP hybrid functional are underestimated with respect to the CAM-B3LYP results. For functional CAM-B3LYP three methods were utilized: (i) (simplified) Tamm-Dancoff Approximation ${ }^{94}$, (ii) (simplified) TDDFT $^{95}$ and (iii) full TDA. ${ }^{96}$ Mulliken populations are listed in Table S12 and for the ground state these values are similar to those calculated using standard DFT, whereas energies of excited states are listed in Table S13. Local charges and spins are almost identical for methods (i) and (ii), but energies of STDA and TDA (Table S13) are closer to those calculated using multiconfigurational SCF methods. Since molecules possess the $C_{1}$ symmetry, the Kohn-Sham orbitals (microstates) in the ground state may be degenerated only due to accidental degeneracy of spin orbitals. One-electron occupancies of microstates contributing to the ground state were therefore studied and B3LYP results show (due to finite electronic smearing) approximate order of KS orbitals with major contribution of atomic $3 d$ orbital as follows: the lowest energy microstate is the doubly occupied $3 d x z$ and ( $\alpha$ spinorbital) $3 d z^{2}$ with minor admixture of $3 d x^{2}-y^{2}$, followed by $3 d y z$ and $3 d x y$ orbitals. Next is well separated in energy $3 d x^{2}-y^{2}$, which is the closest occupied orbital to the Fermi level. First unoccupied orbital is $3 d z^{2}$ with minor admixture of $3 d x^{2}-y^{2}$ ( $\beta$ spinorbital). Occupied ( $\alpha$ spinorbital) counterpart of this spinorbital is the $3 d z^{2}$ lying near $3 d x z$ microstate. Electron occupying this orbital gives main contribution to the magnetic moment. Grouping of electrons is similar to that for higher symmetry cubic case for
$3 d^{9}$ ions, namely the degenerated state $t_{2 g}(3 d x y, 3 d y z, 3 d x z)$ is separated from the degenerated state $e_{g}\left(3 d x^{2}-y^{2}, 3 d z^{2}\right)$ lying closer to the Fermi level. The real $3 d$ orbitals are expressed in the Cartesian molecular axis system (CMAS) defined in Section $\mathrm{V}$ in SI. All 4 excited states within the ground multiplet ${ }^{2} \mathrm{D}$ of $\mathrm{Cu}\left(\mathrm{II} ; 3 d^{9}\right)$ ion originate from excitations of electron density from occupied orbitals to only one $\beta$ unoccupied orbital closest to Fermi level (number 167b in ORCA output). This microstate has mainly $3 d z^{2}$ character consistent with DFT results where unpaired electron (lone hole) in the ground state is of such symmetry. First excited state results mainly from excitation of $3 d x^{2}-y^{2}$ electron to $167 \mathrm{~b}$ state, so we could approximate such state with hole on $3 d x^{2}-y^{2}$ orbital. Second and third excited states result from excitation of electron from $d x y$ and $3 d y z$ orbitals, fourth from $3 d x z, 3 d y z$ and $3 d x y$ orbitals. Since TDDFT excited states are due to the $d$-electron excitations similarly as in the crystal field (CF) picture, we assume that such TDDFT states correspond to the CF states. This is confirmed by calculations using CASSCF methods (see below).

\subsubsection{CASSCF excited state calculations}

To account for dynamic correlations, multiconfigurational-SCF calculations were performed using CASSCF method with additional perturbations NEVPT2. For $\mathrm{Cu}(\mathrm{II})$ ion we choose the active space consisting of five orbitals with major contribution of $3 d$ atomic states with 9 electrons that could occupy them. Self-convergence procedure leads to five states well separated from each other in energy scale, i.e. orbital singlets (Table 3).

Table 3. Energies of the excited states w.r.t. the ground state (in $\mathrm{cm}^{-1}$ ) calculated using CASSCF and NEVPT2 for compound $\mathbf{1}$ and $\mathbf{2}$.

\begin{tabular}{|c|c|c|c|c|c|}
\hline $\begin{array}{c}\text { Excited } \\
\text { state }\end{array}$ & $\begin{array}{c}\text { CASSCF } \\
\mathbf{1}\end{array}$ & $\begin{array}{c}\text { NEVPT2 } \\
\mathbf{1}\end{array}$ & $\begin{array}{c}\text { CAM-B3LYP } \\
\text { TDA 1 }\end{array}$ & $\begin{array}{c}\text { CASSCF } \\
\mathbf{2}\end{array}$ & $\begin{array}{c}\text { NEVPT2 } \\
\mathbf{2}\end{array}$ \\
\hline 1st & 9699 & 12680 & 12574 & 9972 & 12282 \\
\hline 2nd & 10420 & 14255 & 17761 & 10547 & 14048 \\
\hline 3rd & 12212 & 16186 & 17907 & 12134 & 16421 \\
\hline 4th & 12262 & 16215 & 18578 & 13228 & 18030 \\
\hline
\end{tabular}

Calculations for compound $\mathbf{1}$ show that the ground state consists of total $93 d$ electrons in two major configurations: (i) with unpaired $3 d z^{2}$ electron ( 70\%) and (ii) with unpaired $3 d \mathrm{x}^{2}-$ $y^{2}$ electron ( $\left.29 \%\right)$. The 1st excited state is similar to the ground state but proportions are nearly inverted for (ii) with unpaired $3 d x^{2}-y^{2}$ electron ( 68\%) and (i) with unpaired $3 d z^{2}$ electron ( 29\%). Other excited states correspond to the following configurations: 2nd - with unpaired $3 d x z$ electron, 3rd - with unpaired $3 d x y$ electron, and 4 th - with unpaired $3 d y z$ electron. This is consistent with level schemes for low symmetries from literature ${ }^{97}$ and with our semiempirical results and partially also TDDFT. Calculations for compound $\mathbf{2}$ show that the ground state consists of total $93 d$ electrons in two major configurations: (i) with unpaired $3 d z^{2}$ electron ( 77\%) and (ii) with unpaired $3 d x^{2}-$ $\mathrm{y}^{2}$ electron ( 22\%). The 1st excited state consists of two configurations: (i) with unpaired $3 d x z$ electron ( $51 \%)$ and (ii) with unpaired electron $3 d x^{2}-y^{2}(\sim 39 \%)$. The 2 nd excited state is similar to the 1st excited state but proportions are different for (ii) with unpaired $3 d x^{2}-y^{2}$ electron ( $37 \%$ ) and (i) with unpaired $3 d x z$ electron ( $42 \%)$. Other excited states correspond to the following configurations: $3 r d$ - with unpaired $3 d y z$ electron and 
4 th - with unpaired $3 d x y$ electron. The 3 rd and 4 th excited state are well separated, suggesting that structure $\mathbf{2}$ is geometrically more distorted than structure $\mathbf{1}$. This would mean that it is associated with the solvent-dependent plane (N2-N9-N17- $\left.\mathrm{H}_{2} \mathrm{O}\right)$ as observed in Section 2.3 (S-value $\mathbf{2}=0.308$ vs S-value $\mathbf{1}=$ 0.077 ) and can be directly related to the observed magnetism differences and the literature examples of porphyrins/phthalocyanines, which facilitate SIM/qubit behavior for symmetry reasons. ${ }^{46,55-59}$

The inclusion of NEVPT2 dynamic corrections for compound 1 shifts the $1^{\text {st }}$ excited state $\sim 3000 \mathrm{~cm}^{-1}$ up from the ground state, and $\sim 4000 \mathrm{~cm}^{-1}$ for the $2^{\text {nd }}, 3^{\text {rd }}$ and $4^{\text {th }}$ exited states. Difference between the $1^{\text {st }}$ excited state and $2^{\text {nd }}$ excited state is enlarged from $\sim 700 \mathrm{~cm}^{-1}$ to $\sim 1600 \mathrm{~cm}^{-1}$. Differences between the higher excited states obtained by CASSCF and NEVPT2 are similar. This suggests that dynamical correlations are most relevant for the two lowest states with the unpaired $3 d x^{2}-y^{2}$ and $3 d z^{2}$ electrons contributing to the magnetic moment. Because accurate description of electronic correlations is crucial for optical spectra, the $a b$ initio results are next mapped on effective models to allow comparison with CF energy levels and semiempirical results in Sections 2.8 and 2.10 respectively.

The MC-SCF Mulliken occupations of the selected atoms show some difference with respect to DFT results. Most important is the fact that the spin is more strongly localized at the $\mathrm{Cu}$ site and electronic charge is closer to nominal charge 2+ (Table S10). Charges on atoms neighboring with $\mathrm{Cu}$ are larger than those from DFT. Spins on these neighboring atoms are very small. This is also supported by Loewdin analysis (Table S14). Nonrelativistic CASSCF excited states are well separated from the ground state (GS) and this separation is significantly enlarged with inclusion of dynamic correlations at NEVPT2 level.

Due to such large separations, the mixing of states by SOC is small. The Kramers doublet states resulting from action of SOC (Table S15) indicate that the relative energies are slightly changed with exception of $3^{\text {rd }}$ and $4^{\text {th }}$ excited states, which are now clearly separated in energy, while each being a Kramers doublet, as expected for $S=1 / 2$. We have listed compositions of wavefunctions for one chosen state from each Kramers doublet for compounds $\mathbf{1}$ and $\mathbf{2}$ in Table S16. Such states consist of two components: $\left|S,+M_{S}\right\rangle$ and $\left|S,-M_{S}\right\rangle$ with respective mixing coefficients. Second states from each Kramers doublet have mixing coefficients interchanged for the components $\left|S,+M_{S}\right\rangle$ and $\left|S,-M_{S}\right\rangle$. In the case of compound 1 three lowest KD states consist mainly of one chosen spin free state (i.e. root) with arbitrary spin direction with minor addition of the second spin free state with spin of opposite direction. The fourth and fifth KD states are mixtures of spin free states originating from two roots, which are the $3^{\text {rd }}$ and $4^{\text {th }}$ excited NEVPT2 states. This is not surprising since the latter ones are relatively closer in energy and SOC mixes them stronger. For compound $\mathbf{2}$, since all NEVPT2 spin free states are well separated, KD states are only mixtures of states originating from one root.

\subsubsection{Calculations of spectroscopic splitting factors $\mathbf{g}$}

The $\boldsymbol{g}$-tensor components $\left(g_{x}, g_{y}, g_{z}\right)$ were calculated in the principal axis system (PAS) using ZORA approach (Table 4, Table S17). Results indicate large difference between $g_{\mathrm{z}}$ and $\left(g_{\mathrm{x}}, g_{\mathrm{y}}\right)$, whereas $g_{\mathrm{x}}$ and $g_{\mathrm{y}}$ differ slightly since our system has $C_{1}$ symmetry. The main magnetic axes, which correspond to the PAS of Zeeman Hamiltonian ${ }^{98}$, do not exactly correspond to the

Table 4. The $g$-tensor components for compounds $\mathbf{1}$ and $\mathbf{2}$ in the principal axis system (PAS) using ZORA approach.

\begin{tabular}{|c|c|c|c|c|c|}
\hline $\begin{array}{c}\boldsymbol{g}- \\
\text { tensor }\end{array}$ & CASSCF & NEVPT2 & CASSCF & NEVPT2 & B3LYP DFT \\
\hline$g_{\mathrm{x}}$ & 2.081 & $\mathbf{1}$ & $\mathbf{2}$ & $\mathbf{2}$ & $\mathbf{1}$ \\
\hline$g_{\mathrm{y}}$ & 2.115 & 2.067 & 2.074 & 2.058 & 2.048 \\
\hline$g_{\mathrm{z}}$ & 2.517 & 2.386 & 2.511 & 2.409 & 2.177 \\
\hline
\end{tabular}

molecular bonds of $\mathrm{Cu}$ and neighboring atoms but are lying closely. CASSCF method overestimate the $\boldsymbol{g}$-factors with respect to NEVPT2 method, so $\left(g_{\mathrm{i}}\right)$ components derived from the latter one conform well to experimental data for axial symmetry $\mathrm{Cu}(\mathrm{II})$ systems. ${ }^{99-102}$ We have also listed B3LYP results with the basis aug-cc-pVTZ-J and CP(PPP) for $\mathrm{Cu}$ atom with extra fineness of the grid to get more accurate values of the $\boldsymbol{g}$ tensor. Products of magnetic susceptibilities and temperature $\chi T=\partial^{2} E / \partial B^{2}$ for compounds $\mathbf{1}$ and $\mathbf{2}$ obtained using NEVPT2 are plotted in Figure S32. Preliminary plots of EPR spectra (Figures S26 and S27 and Section 2.7) obtained using MOLCAS ${ }^{89}$ and $\mathrm{PHI}^{80}$ support the conclusion that hyperfine structure might be important in such simulations.

\subsection{SPM and MSH analysis}

As discussed in Section $\mathrm{VII}$ in $\mathrm{SI}$, in order to gain initial assessment of the $g_{\mathrm{i}}$ factors, simplified $\mathrm{MSH}$ formulas were employed. ${ }^{97,} 103$ These initial estimates have indicated general suitability of the MSH approach. For more accurate calculations of SHPs, the MSH formulas for tetragonal (TE) 104-110 and orthorhombic ${ }^{111-113}$ symmetry is applied. First, to obtain input data for MSH formulas, the CFPs $\mathrm{B}_{\mathrm{kq}}{ }^{114-116}$ are calculated using SPM for $\mathrm{Cu}(\mathrm{II})$ centers in $\mathbf{1}$ and $\mathbf{2}$ using the structural data for set $\mathrm{C}_{2 \mathrm{v}}$ (Section $\mathrm{V}$ in $\mathrm{SI}$ ). The two plausible $D q$ values $\sim 1015 \mathrm{~cm}^{-1}$ and $\sim 1285 \mathrm{~cm}^{-1}$ estimated by us experimentally from optical spectra (Section 2.8) are adopted. Pertinent comments on reliability of usage of SPM/CFP predictions as input data for MSH formulas are provided in Section VII in SI. The results listed in Table 5 indicate that after standardization (see Section VII in SI) the axial CFP $B_{20}$ of the highest magnitude and minimal values of $B_{22}$ and $B_{42}$ are obtained, while $B_{20}$ and $B_{22}$ also change signs along the choice of positive rhombicity ratio built into CST package. ${ }^{117,118}$

Table 5. The CFPs in Wybourne notation $\mathrm{B}_{\mathrm{kq}}\left(\right.$ in $\mathrm{cm}^{-1}$ ) calculated using SPM with $D q \sim$ $1285 \mathrm{~cm}^{-1}$ and $D q \sim 1015 \mathrm{~cm}^{-1}$ for set $C_{2 \mathrm{v}}$.

\begin{tabular}{|c|c|c|c|c|c|c|c|c|}
\hline & \multicolumn{9}{|c|}{ Complex 1 } & \multicolumn{5}{c|}{ Complex 2 } \\
\hline CFPs: & \multicolumn{3}{|c|}{$\mathrm{C}_{2 \mathrm{v}}$} & \multicolumn{1}{|c|}{$\mathrm{C}_{2 \mathrm{v}}$ after OR/ST* } & \multicolumn{2}{c|}{$\mathrm{C}_{2 \mathrm{v}}$} & \multicolumn{2}{c|}{$\mathrm{C}_{2 \mathrm{v}}$ after OR/ST* } \\
\hline $\mathrm{Dq}$ & 1285 & 1015 & 1285 & 1015 & 1285 & 1015 & 1285 & 1015 \\
\hline $\mathrm{B}_{20}$ & 15931 & 12584 & - & - & 16017 & 12651 & - & - \\
\hline & & & 28719 & 22685 & & & 26735 & 21118 \\
\hline $\mathrm{B}_{22}$ & 16945 & 13385 & -1283 & -1014 & 15290 & 12078 & -2163 & -1708 \\
\hline $\mathrm{B}_{40}$ & 31528 & 24889 & 21424 & 16913 & 30963 & 24443 & 21239 & 16767 \\
\hline $\mathrm{B}_{42}$ & -8102 & -6396 & -1712 & -1351 & -7429 & -5864 & -1279 & -1010 \\
\hline $\mathrm{B}_{44}$ & 15305 & 12082 & 23758 & 18756 & 14822 & 11701 & 22958 & 18123 \\
\hline & & & & & & & & \\
\hline
\end{tabular}

* The orthorhombic transformation (OR/ST) defined as S2 ${ }^{113}, 117,119,120:(X, Y, Z) \rightarrow$ $(X,-Z, Y)$ was applied. 
The relations between the CF energy levels in Eqs (S6) and (S7) and those $E_{1}$ and $E_{2}$ employed in $\mathrm{MSH}$ formulas for tetragonal symmetry in ${ }^{105,108}$ are as follows:

$$
\begin{aligned}
& E_{1}=10 D q=\Delta E=\left(\left|d x^{2}-y^{2}>-\right| d x y>\right) \\
& E_{2}=10 D q-3 D s+5 D t=\Delta \mathrm{E}=\left(\left|d x^{2}-y^{2}>-\right| d y z>\right)=\Delta \mathrm{E}=\left(\mid d x^{2}-y^{2}>-\right. \\
& \mid d x z>)
\end{aligned}
$$

In Eq. (1) $D q$ denotes the cubic CFP, whereas $D s$ and $D t$ denote the second-and fourth-rank tetragonal CFPs in the conventional notation ${ }^{121}, 122$, respectively. Depending on the shape of the distorted octahedron (Section 2.3) and thus the strength of tetragonal CFPs, the ground state may be either $\mid d x^{2}-y^{2}>$ or $\mid d z^{2}>.97,103$ This is also evident in our ab initio calculations (Section 2.9). Next, using the CFPs in Table 5 and the conversion relations between the CFPs $B_{k q}$ and $(D s, D t)$ given in ${ }^{11,14,122}$, the latter CFPs are calculated, and subsequently, the energies $E_{1}$ and $E_{2}$ in Eq. (1). Finally, the tetragonal SHPs: $g_{\mathrm{i}}$ and $A_{\mathrm{i}}$ are calculated applying the respective MSH formulas. ${ }^{105,} 108$ To calculate the hyperfine structure parameters $A_{i}$ we employ analogous MSH formulas derived as functions of the $g_{\mathrm{i}}$ values and respective CF energies. ${ }^{104-110}$

For orthorhombic symmetry ${ }^{111-113}$, four CF energies $E_{\mathrm{i}}(i=1-4)$ apply. The corresponding relations are:

$E_{1}=10 D q$

$E_{2}=10 D q+3 D s-5 D t-3 D_{\xi}+4 D \eta^{2}$

$E_{3}=10 D q+3 D s-5 D t+3 D_{\xi}-4 D \eta^{2}$

$E_{4}=-4 D s-5 D t$

In Eq. (2) $D q, D s$ and $D t$ have the same meaning as in Eq. (1), whereas $D_{\xi}$ and $D_{\eta}$ are the conventional orthorhombic CFPs, which are related to the CFPs $B_{k q}$. The orthorhombic (OR) SHPs $g_{\mathrm{i}}$ and $A_{\mathrm{i}}$ calculated applying the respective MSH formulas ${ }^{111-113}$ are listed in Table S19. To facilitate comparison of the orthorhombic $g_{\mathrm{i}}$ and $A_{\mathrm{i}}$ components and the perpendicular tetragonal ones, the averaged values: $\left(g_{\mathrm{x}}+g_{\mathrm{y}}\right) / 2 \sim g_{\perp}$ and $\left(A_{\mathrm{x}}+A_{\mathrm{y}}\right) / 2 \sim A_{\perp}$ are also calculated, while the axial components are directly comparable: $g_{z} \sim g_{\|}$and $A_{z} \sim A_{\|}$.

Three important points bearing on interpretation of results in Table S19 must be kept in mind as discussed in Section VII in SI. In view of these points, analysis of the results in Table S19 leads to the following conclusions. The SHPs $g_{\mathrm{i}}$ and $A_{\mathrm{i}}$ calculated using MSH formulas for the TE case may be directly compared with experimental results in Section 2.3, whereas those for the orthorhombic (OR) case - with the ab initio results in Section 2.9. Results for both cases indicate good mutual consistency, which shows the usefulness of the ascent/descent in symmetry. ${ }^{123-125}$ Employing the standardized CFP sets in MSH calculations is even more crucial in the TE case than in the OR case, in view of additional approximations involved in the TE case, i.e. omitting the orthorhombic CFPs: $\mathrm{B}_{22}$ and $\mathrm{B}_{42}$.

The values of $g_{i}$ calculated in Table S19 by adopting TE and OR formulas agree well with our experimental ones: $g_{\|}=2.26$ and $g_{\perp}=2.05$ for complex 1 and also with literature data obtained for compounds with axial symmetry Cu-sites, see
Table S20. Since EPR spectra were done on powdered samples, the axes $(x, y, z)$ implicitly involved in experimental values: $g_{\|}(z)$, $g_{\perp}(x, y)$ may be considered only as nominal principal axes. To relate the axes $(x, y, z)$ directly to the crystal structure, e.g. to find out if the $z$-axis corresponds to the orientations of the long axis of the coordination octahedron (Figures 1c, d), EPR measurements on powdered microcrystalline samples would be required. Comparison of the theoretical $A_{\mathrm{i}}$ values in Table S19 with our experimental value $A_{\|}=175(\mathrm{G})=165.8\left(10^{-4} \mathrm{~cm}^{-1}\right)$ for complex 1 and the respective values in Table S20 reveals that all experimental $A_{\|}$are positive, whereas theoretical ones are negative. This is due to the limited capabilities of the computer program used, have allowed fitting EPR spectra only with the absolute values of the hyperfine interaction parameters $|A|$. Since no perpendicular splitting has been observed in EPR spectrum, no accurate value of $A_{\perp}$ could be determined. Attempts to simulate spectra using $A_{\perp}$ indicate that this is not a sensitive parameter because any splitting is hidden in the main EPR line. A good match has been obtained with $A_{\perp}$ equal 1 as well as $20 \mathrm{~cm}^{-1}$. Both formulas: $T E$ and $O R$ ones, yield comparable sets of results and indicate that good agreement may be obtained by appropriate matching of the adjustable parameters. However, overall the $D q$ value (in $\mathrm{cm}^{-1}$ ) 1015 seems better than 1285 , which yields larger CF energies $\left(E_{\mathrm{i}}\right)$. This finding conforms to that obtained in Section 2.8. Comparison of the TE and OR results for sets $C_{2 v}$ or both complexes $\mathbf{1}$ and $\mathbf{2}$ in Table S19 indicates smaller differences between the respective results than those for sets $C_{2 v}$ after OR/ST. This may be due to the approximations involved in the TE case. Since no such approximations are involved in the OR case, the results for sets $\mathrm{C}_{2 \mathrm{v}}$ after OR/ST may be considered as more accurate. Comparison of the results in Table S19 and the respective results obtained by $a b$ initio methods (Section 2.9) also favor the MSH results obtained with lower $D q$ value for sets $C_{2 v}$ after OR/ST. Importantly, the CF energies obtained for sets $C_{2 v}$ do not agree as well those for sets $C_{2 v}$ after OR/ST. This reinforces the importance of employing orthorhombic standardization.

Diagonalization ${ }^{126,127}$ of the $\mathrm{CF}$ Hamiltonian $\mathrm{H}_{\mathrm{CF}}$ using the correspondence between spin $S=2$ states and spin $L=2$ states is anticipated in the future studies. Calculations of the CF energy levels and composition of the $\left|L=2, M_{L}>=\right| M_{L}>$ states will enable assessment of their dominant contributions and thus verification if the semiempirically predicted ground state conforms to that obtained by optical spectroscopy and $a b$ initio methods. In order to allow a better correlation of overall results, an attempt will be made to fit raw EPR data using orthorhombic $g_{\mathrm{i}}$ and $A_{\mathrm{i}}$ components as well.

\section{Conclusions}

We prepared a modular organic system for in-depth studies on how subtle structural differences can affect magnetic relaxation properties in transition metal coordination compounds. Tunable capability of synthesized complexes comes from: (i) novel pentadentate $\mathbf{L}^{\text {red-R }} \mathrm{N}, \mathrm{O}$-aminal ligand formed by unexpected in situ reduction of the parent Schiff base ligand $\mathbf{L}$; (ii) the chosen solvent/reagent alcohol; (iii) coordination 
preferences of metal salt and its counterion. Considering that the SIM-active $d^{9}$ coordination compounds are rarely encountered, two structurally similar octahedral $\mathrm{Cu}$ (II) compounds were prepared as the case study. Both analogues were revealed to be rare examples of magnetically isolated copper system that display slow relaxation of magnetisation, with phenomenon being more pronounced for the perchlorate analogue 1 than the triflate $2 .{ }^{42}$ Extensive series of experimental techniques and theoretical approaches allowed us to understand the effect of geometrical and structural changes on copper(II) electronic states and consequently observed magnetic behaviour. It is predominantly the result of: (i) the octahedral structural distortions exerted by the alkoxy groups appended on the $\mathbf{L}^{\text {red-1/2 }}$ scaffold; (ii) spatial arrangements of the $\mathrm{Cu}(\mathrm{II})---\mathrm{Cu}$ (II) pairs in the unit cell due to the pyridine/oxazoline crystal packing contacts. This translates to the character of the hyperfine structure observed in the EPR spectra as a function of temperature and applied frequencies, related to the interactions of $\mathrm{S}=1 / 2$ electron spin of $\mathrm{Cu}(\mathrm{II})$ ion with the nuclear spin $I=3 / 2$. In 1 , the more square planar character within the N3O ligand-solvent plane and slow magnetic relaxation phenomenon is more pronounced than in $\mathbf{2}$, despite the inherently detrimental effect of the nitrogen atoms.60 Relaxation of magnetization proceeds through the combination of Raman, direct and QTM processes.

To gain further understanding of the magnetic studies, an extensive series of $a b$ initio ((TD-)DFT, CASSCF, NEVPT2) and semiempirical (SPM, MSH) calculations was also conducted. $\mathrm{Cu}(\mathrm{II})$ electronic states, $g$-tensor and $A$-tensor components as well as ligand field parameters were calculated and compared with the experimentally determined values. Specifically, such thorough and combined utilization of several experimental techniques and theoretical approaches for $\mathrm{Cu}(\mathrm{II})$ ions was performed for the first time, which will delineate possibilities and limitations of this combined strategy in the future. It appears that the close-lying energetic states of $\mathrm{Cu}(\mathrm{I}) / \mathrm{Cu}(\mathrm{II})$ could possibly also affect much faster relaxation in $\mathbf{2}$, which shows that factors other than structural distortions need to be accounted for the design of potential $\mathrm{Cu}$ (II)-based nanomagnets as well. We anticipate that results of this study will facilitate rational design of the synthesis and thus in-depth characterization of new $\mathrm{Cu}(\mathrm{II}) \mathrm{SIMs} / q u b i t s$ in the future. Specifically, presented modular platform can be further utilized for magneto-structural correlations in other magnetic systems, which we are currently investigating further.

\section{Associated content}

\section{Author Information}

\section{Corresponding Authors}

Adam Gorczyński - ${ }^{a}$ Faculty of Chemistry, Adam Mickiewicz University, Uniwersytetu Poznańskiego 8, 61-614 Poznań, Poland; Email: adam.gorczynski@amu.edu.pl; ORCID: 00000002-3930-8489
Maria Korabik - e Faculty of Chemistry, University of Wrocław, $F$. Joliot-Curie 14, 50-383 Wrocław, Poland; Email: maria.korabik@chem.uni.wroc.pl; ORCID: 0000-0002-99709743

\section{Authors}

Dawid Marcinkowski - aFaculty of Chemistry, Adam Mickiewicz University, Uniwersytetu Poznańskiego 8, 61-614 Poznań, Poland; ORCID: 0000-0001-6053-3229

Ariel Adamski - a Faculty of Chemistry, Adam Mickiewicz University, Uniwersytetu Poznańskiego 8, 61-614 Poznań, Poland; ORCID: 00000003-3205-6968

Maciej Kubicki - a Faculty of Chemistry, Adam Mickiewicz University, Uniwersytetu Poznańskiego 8, 61-614 Poznań, Poland; ORCID: 00000001-7202-9169

Giuseppe Consiglio - ${ }^{b}$ Dipartimento di Scienze Chimiche, Università di Catania, I-95125 Catania, Italy; ORCID: 0000-0002-2682-269X

Violetta Patroniak - aFaculty of Chemistry, Adam Mickiewicz University, Uniwersytetu Poznańskiego 8, 61-614 Poznań, Poland; ORCID 0000-0001-9976-7233

Tomasz Ślusarski - a Faculty of Chemistry, Adam Mickiewicz University, Uniwersytetu Poznańskiego 8, 61-614 Poznań, Poland; 'Institute of Spintronics and Quantum Information, Faculty of Physics, Adam Mickiewicz University, Uniwersytetu Poznańskiego 2, 61-614 Poznań, Poland; ORCID: 0000-0003-3269-1558

Muhammed Açıkgöz - ${ }^{d}$ Department of Science, The State University of New York (SUNY) Maritime College, New York 10465, USA; ORCID: 0000-0003-4165-0854

Daria Szeliga - e Faculty of Chemistry, University of Wrocław, F. JoliotCurie 14, 50-383 Wrocław, Poland; ORCID: 0000-0001-7656-3107

Nahir Vadra - aFaculty of Chemistry, Adam Mickiewicz University, Uniwersytetu Poznańskiego 8, 61-614 Poznań, Poland; fUniversidad de Buenos Aires, Facultad de Ciencias Exactas y Naturales, Departamento de Química Inorgánica, Analítica y Química Física and CONICET-Universidad de Buenos Aires, Instituto de Química Física de los Materiales, Medio Ambiente y Energía (INQUIMAE), Buenos Aires C1428EGA, Argentina; ORCID: 0000-0001-5652-926X

Mirosław Karbowiak - e Faculty of Chemistry, University of Wrocław, F. Joliot-Curie 14, 50-383 Wrocław, Poland; ORCID: 0000-0001-70778481

Ireneusz Stefaniuk - ${ }^{\mathrm{g}}$ College of Natural Sciences, University of Rzeszow, Rejtana 16a, 35-310 Rzeszow, Poland; ORCID: 0000-00032616-9595

Czesław Rudowicz - aFaculty of Chemistry, Adam Mickiewicz University, Uniwersytetu Poznańskiego 8, 61-614 Poznań, Poland; ORCID: 0000-0003-0370-9392

\section{CRediT authorship contribution statement}

Dawid Marcinkowski: Synthesis of chemical compounds, magneto-structural correlations: Conceptualization, 
Methodology, Formal analysis, Investigation, Resources, Data curation, Writing - original draft, Writing - review \& editing, Visualization.

Ariel Adamski: Synthesis of chemical compounds: Conceptualization, Methodology, Formal analysis, Investigation, Resources, Data curation, Writing - review \& editing, Visualization.

Maciej Kubicki: Crystallographic studies: Formal analysis, Investigation, Data curation, Writing - review \& editing, Visualization.

Giuseppe Consiglio: Synthesis of compounds: Formal analysis, Investigation, Data curation, Writing - review \& editing.

Violetta Patroniak: Methodology, Formal analysis, Investigation, Writing - review \& editing, Supervision.

Tomasz Ślusarski: Theoretical studies: DFT/ab initio calculations, Formal analysis, Investigation, Data curation, Writing - review \& editing, Visualization.

Muhammed Açıkgöz: Theoretical studies: SPM and MSH calculations, Formal analysis, Investigation, Data curation, Writing - review \& editing, Visualization.

Daria Szeliga: DC/AC magnetism studies: Formal analysis, Investigation, Data curation, Writing - review \& editing, Visualization.

Nahir Vadra: Magneto-structural correlations: Data curation, Writing - review \& editing, Visualization.

Mirosław Karbowiak: Spectroscopic and theoretical studies: Conceptualization, Methodology, Formal analysis, Investigation, Resources, Data curation, Writing - review \& editing, Visualization.

Ireneusz Stefaniuk: EPR studies: Conceptualization, Methodology, Formal analysis, Investigation, Resources, Data curation, Writing - review \& editing, Visualization.

Czesław Rudowicz: Magneto-structural correlations, analysis of SPM, MSH and DFT/ab initio results, Conceptualization, Methodology, Formal analysis, Investigation, Resources, Data curation, Writing - review \& editing, Visualization, Supervision, Funding acquisition.

Adam Gorczyński: Magneto-structural analysis and correlations: Conceptualization, Methodology, Formal analysis, Investigation, Resources, Data curation, Writing - original draft, Writing - review \& editing, Visualization, Supervision.

Maria Korabik: DC/AC magnetism studies, EPR studies: Conceptualization, Methodology, Formal analysis, Investigation, Resources, Data curation, Writing - review \& editing, Visualization, Supervision.

\section{Funding}

This work was mainly supported by: (PI: CZR): UMO2016/21/B/ST4/02064 from the Polish National Science Center and partially from the budget for science in 2018-2020, as a part of the Polish Ministry of Science and Higher Education project; (PI: DM): Grant No. 0088/DIA/2018/47 in the frame of the "Diamond Grant" programme; (PI: AG): SONATA grant UMO2020/39/D/ST4/01182 from National Science Centre, Poland. Dawid Marcinkowski is a scholarship holder of the Adam Mickiewicz University Foundation for the academic year
2021/2022. The calculations were made at the Poznan Supercomputing and Networking Center. conflicts to declare.

\section{Conflicts of interest}

There are no conflicts to declare.

\section{Acknowledgements}

Dedicated to Professor Stefan Lis on the occasion of his 70th birthday. Technical assistance with impulse EPR measurements from M.Sc. B. Cieniek is much appreciated.

\section{References}

1. E. Coronado, Nat. Rev. Mater, 2019, DOI: 10.1038/s41578019-0146-8.

2. C. A. P. Goodwin, Dalton Transactions, 2020, 49, 1432014337.

3. A. Zabala-Lekuona, J. M. Seco and E. Colacio, Coordination Chemistry Reviews, 2021, 441, 213984.

4. C. E. Jackson, I. P. Moseley, R. Martinez, S. Sung and J. M. Zadrozny, Chemical Society Reviews, 2021, 50, 6684-6699.

5. R. Mirzoyan, N. P. Kazmierczak and R. G. Hadt, Chemistry A European Journal, 2021, 27, 9482-9494.

6. M. S. Fataftah and D. E. Freedman, Chemical Communications, 2018, 54, 13773-13781.

7. M. Affronte, J. Mater. Chem., 2009, 19, 1731-1737.

8. E. Moreno-Pineda and W. Wernsdorfer, Nature Reviews Physics, 2021, DOI: 10.1038/s42254-021-00340-3.

9. K. Head-Marsden, J. Flick, C. J. Ciccarino and P. Narang, Chemical Reviews, 2021, 121, 3061-3120.

10. K. S. Pedersen, A.-M. Ariciu, S. McAdams, H. Weihe, J. Bendix, F. Tuna and S. Piligkos, J. Am. Chem. Soc., 2016, 138, 5801-5804.

11. A. Gaita-Ariño, H. Prima-García, S. Cardona-Serra, L. Escalera-Moreno, L. E. Rosaleny and J. J. Baldoví, Inorg. Chem. Front., 2016, 3, 568-577.

12. M. Atzori and R. Sessoli, J. Am. Chem. Soc. , 2019, 141, 11339-11352.

13. A. Gaita-Ariño, F. Luis, S. Hill and E. Coronado, Nat. Chem., 2019, 11, 301-309.

14. C.-J. Yu, S. von Kugelgen, D. W. Laorenza and D. E. Freedman, ACS Central Science, 2021, 7, 712-723.

15. S. E. Crawford, R. A. Shugayev, H. P. Paudel, P. Lu, M. Syamlal, P. R. Ohodnicki, B. Chorpening, R. Gentry and Y. Duan, Advanced Quantum Technologies, n/a, 2100049.

16. S. Krastanov, M. Heuck, J. H. Shapiro, P. Narang, D. R Englund and K. Jacobs, Nature Communications, 2021, 12, 191.

17. R. S. D. Gatteschi, J. Villain, Molecular Nanomagnets, Oxford University Press, Oxford, 2006.

18. F. L. J. Bartolomé, J.F. Fernández, Molecular Nanomagnets: Physics and Applications, Springer-Verlag Berlin, Heidelberg, 2014.

19. D. G. C. Benelli, Introduction to Molecular Magnetism: From Transition Metals to Lanthanides, Wiley- $\mathrm{VCH}$, Weinheim 2015.

20. M. M. R.A. Layfield, Lanthanides and Actinides in Molecular Magnetism, Wiley-VCH, Weinheim 2015. 
P. Z. J. Tang, Lanthanide Single Molecule Magnets, Springer-Verlag Berlin Heidelberg, 2015.

22. E. S. Gao, Molecular Nanomagnets and Related Phenomena, Structure and Bonding, Springer-Verlag Berlin, Heidelberg, 2015.

23. R. Sessoli, D. Gatteschi, A. Caneschi and M. A. Novak, Nature, 1993, 365, 141-143.

24. S. Gómez-Coca, D. Aravena, R. Morales and E. Ruiz, Coord. Chem. Rev., 2015, 289-290, 379-392.

25. A. B. Canaj, S. Dey, E. R. Martí, C. Wilson, G. Rajaraman and M. Murrie, Angew. Chem. Int. Ed., 2019, 58, 14146-14151. Y.-S. Ding, N. F. Chilton, R. E. P. Winpenny and Y.-Z. Zheng, Angew. Chem. Int. Ed., 2016, 55, 16071-16074.

27. Z.-H. Li, Y.-Q. Zhai, W.-P. Chen, Y.-S. Ding and Y.-Z. Zheng, Chem. Eur. J., 2019, 25, 16219-16224.

$28 . \quad$ J. M. Frost, K. L. M. Harriman and M. Murugesu, Chem. Sci., 2016, 7, 2470-2491.

29. G. A. Craig and M. Murrie, Chem. Soc. Rev., 2015, 44, 2135 2147

F.-S. Guo, B. M. Day, Y.-C. Chen, M.-L. Tong, A. Mansikkamäki and R. A. Layfield, Sci., 2018, 362, 1400. C. A. P. Goodwin, F. Ortu, D. Reta, N. F. Chilton and D. P. Mills, Nature, 2017, 548, 439-442.

32. F.-S. Guo, B. M. Day, Y.-C. Chen, M.-L. Tong, A. Mansikkamäki and R. A. Layfield, Angewandte Chemie International Edition, 2017, 56, 11445-11449.

33. K. Randall McClain, C. A. Gould, K. Chakarawet, S. J. Teat, T. J. Groshens, J. R. Long and B. G. Harvey, Chemical Science, 2018, 9, 8492-8503.

34. M. J. Giansiracusa, A. K. Kostopoulos, D. Collison, R. E. P. Winpenny and N. F. Chilton, Chem. Comm., 2019, 55, 70257028.

35. S. E. Stavretis, D. H. Moseley, F. Fei, H.-H. Cui, Y. Cheng, A. A. Podlesnyak, X. Wang, L. L. Daemen, C. M. Hoffmann, M. Ozerov, Z. Lu, K. Thirunavukkuarasu, D. Smirnov, T. Chang, Y.-S. Chen, A. J. Ramirez-Cuesta, X.-T. Chen and Z.-L. Xue, Chem. Eur. J., 2019, 25, 15846-15857. B. Yin and C.-C. Li, Physical Chemistry Chemical Physics, 2020, 22, 9923-9933.

37. A. Castro-Alvarez, Y. Gil, L. Llanos and D. Aravena, Inorganic Chemistry Frontiers, 2020, 7, 2478-2486.

38. Y.-Q. Zhai and Y.-Z. Zheng, Journal of Materials Chemistry C, 2021, 9, 8096-8098.

39.

L. Escalera-Moreno, J. J. Baldoví, A. Gaita-Ariño and E. Coronado, Chemical Science, 2018, 9, 3265-3275.

40. E. Bartolomé, A. Arauzo, J. Luzón, J. Bartolomé and F. Bartolomé, in Handbook of Magnetic Materials, ed. E. Brück, Elsevier, 2017, vol. 26, pp. 1-289.

41. K. S. Pedersen, J. Bendix and R. Clérac, Chem. Comm., 2014 50, 4396-4415.

42. R. Boča and C. Rajnák, Coordination Chemistry Reviews, 2021, 430, 213657.

43 C. Rajnák and R. Boča, Coordination Chemistry Reviews, 2021, 436, 213808.

44. M. Atzori, S. Benci, E. Morra, L. Tesi, M. Chiesa, R. Torre, L. Sorace and R. Sessoli, Inorganic Chemistry, 2018, 57, 731740.

45. E. Coronado, Nature Reviews Materials, 2020, 5, 87-104

46. C.-J. Yu, S. von Kugelgen, M. D. Krzyaniak, W. Ji, W. R. Dichtel, M. R. Wasielewski and D. E. Freedman, Chemistry of Materials, 2020, 32, 10200-10206.
F. Santanni, A. Albino, M. Atzori, D. Ranieri, E. Salvadori, M. Chiesa, A. Lunghi, A. Bencini, L. Sorace, F. Totti and R. Sessoli, Inorganic Chemistry, 2021, 60, 140-151.

48. L. Gu and R. Wu, Physical Review Letters, 2020, 125, 117203.

J. J. Scepaniak, C. S. Vogel, M. M. Khusniyarov, F. W. Heinemann, K. Meyer and J. M. Smith, Sci., 2011, 331, 1049.

50. G. E. Cutsail lii, B. W. Stein, D. Subedi, J. M. Smith, M. L. Kirk and B. M. Hoffman, J. Am. Chem. Soc., 2014, 136, 1232312336.

51. M. Ding, G. E. Cutsail lii, D. Aravena, M. Amoza, M. Rouzières, P. Dechambenoit, Y. Losovyj, M. Pink, E. Ruiz, R. Clérac and J. M. Smith, Chem. Sci., 2016, 7, 6132-6140.

52. I. Bhowmick, A. J. Roehl, J. R. Neilson, A. K. Rappé and M. P. Shores, Chem. Sci., 2018, 9, 6564-6571.

53. R. C. Poulten, M. J. Page, A. G. Algarra, J. J. Le Roy, I. López, E. Carter, A. Llobet, S. A. Macgregor, M. F. Mahon, D. M. Murphy, M. Murugesu and M. K. Whittlesey, J. Am. Chem. Soc., 2013, 135, 13640-13643.

54. W. Lin, T. Bodenstein, V. Mereacre, K. Fink and A. Eichhöfer, Inorg. Chem. , 2016, 55, 2091-2100.

55. M. Warner, S. Din, I. S. Tupitsyn, G. W. Morley, A. M Stoneham, J. A. Gardener, Z. Wu, A. J. Fisher, S. Heutz, C. W. M. Kay and G. Aeppli, Nature, 2013, 503, 504-508.

56. K. Bader, M. Winkler and J. van Slageren, Chem. Comm., 2016, 52, 3623-3626.

57. A. Urtizberea, E. Natividad, P. J. Alonso, M. A. Andrés, I. Gascón, M. Goldmann and O. Roubeau, Adv. Funct. Mater., 2018, 28, 1801695.

58. C.-J. Yu, M. D. Krzyaniak, M. S. Fataftah, M. R. Wasielewski and D. E. Freedman, Chem. Sci., 2019, 10, 1702-1708.

S. von Kugelgen, M. D. Krzyaniak, M. Gu, D. Puggioni, J. M. Rondinelli, M. R. Wasielewski and D. E. Freedman, Journal of the American Chemical Society, 2021, 143, 8069-8077.

60. Y. Dai, Y. Fu, Z. Shi, X. Qin, S. Mu, Y. Wu, J.-H. Su, Y.-F. Deng, L. Qin, Y.-Q. Zhai, Y.-Z. Zheng, X. Rong and J. Du, Chinese Physics Letters, 2021, 38, 030303.

61. M. S. Fataftah, M. D. Krzyaniak, B. Vlaisavljevich, M. R. Wasielewski, J. M. Zadrozny and D. E. Freedman, Chemical Science, 2019, 10, 6707-6714.

62. S. Lenz, K. Bader, H. Bamberger and J. van Slageren, Chemical Communications, 2017, 53, 4477-4480.

R. Boča, C. Rajnák, J. Titiš and D. Valigura, Inorg. Chem., 2017, 56, 1478-1482.

64. H.-H. Cui, W. Lv, W. Tong, X.-T. Chen and Z.-L. Xue, Eur. J. Inorg. Chem., 2019, 2019, 4653-4659.

65. M. Dolai, M. Ali, C. Rajnák, J. Titiš and R. Boča, New J. Chem., 2019, 43, 12698-12701.

66. A. Mielcarek, A. Bieńko, P. Saramak, J. Jezierska and A. Dołęga, Dalton Trans., 2019, 48, 17780-17791.

67. D. V. Korchagin, E. P. Ivakhnenko, O. P. Demidov, A. V. Akimov, R. B. Morgunov, A. G. Starikov, A. V. Palii, V. I. Minkin and S. M. Aldoshin, New Journal of Chemistry, 2021, 45, 21912-21918

68. X. Liang, T.-Y. Zhang, X.-Y. Zeng, Y. Zheng, K. Wei and Y.-R. Yang, J. Am. Chem. Soc., 2017, 139, 3364-3367.

69. G. Huang, B. Kling, F. H. Darras, J. Heilmann and M. Decker, Eur. J. Med. Chem., 2014, 81, 15-21.

70. Y.-Y. Huang, C. Cai, X. Yang, Z.-C. Lv and U. Schneider, ACS Catal., 2016, 6, 5747-5763. 
71.

H. Li, K. M. Belyk, J. Yin, Q. Chen, A. Hyde, Y. Ji, S. Oliver, M. T. Tudge, L.-C. Campeau and K. R. Campos, J. Am. Chem. Soc., 2015, 137, 13728-13731.

72. G. Li, F. R. Fronczek and J. C. Antilla, J. Am. Chem. Soc., 2008, 130, 12216-12217.

73. J. Lu, F. Sha and X.-Y. Wu, Tetrahedron Lett., 2019, 60, 1161-1165.

74. T. Arai, K. Tsuchiya and E. Matsumura, Org. Lett., 2015, 17, 2416-2419.

75.

S. Alvarez, P. Alemany, D. Casanova, J. Cirera, M. Llunell and D. Avnir, Coord. Chem. Rev., 2005, 249, 1693-1708.

76. D. C. M. Llunell, J.Cirera, P.Alemanyand and S.Alvarez, Shape v.2.0, Universitat de Barcelona, 2010. M. Pinsky and D. Avnir, Inorg. Chem., 1998, 37, 5575-5582. S. Khan, S. Herrero, R. González-Prieto, M. G. B. Drew, S. Banerjee and S. Chattopadhyay, New J. Chem., 2018, 42, 13512-13519.

80. 1208.

N. F. Chilton, R. P. Anderson, L. D. Turner, A. Soncini and K. S. Murray, J. Comput. Chem., 2013, 34, 1164-1175.

81. L. Tesi, E. Lucaccini, I. Cimatti, M. Perfetti, M. Mannini, M. Atzori, E. Morra, M. Chiesa, A. Caneschi, L. Sorace and R. Sessoli, Chemical Science, 2016, 7, 2074-2083.

82. M. Atzori, L. Tesi, S. Benci, A. Lunghi, R. Righini, A. Taschin, R. Torre, L. Sorace and R. Sessoli, Journal of the American Chemical Society, 2017, 139, 4338-4341.

83. K. S. Cole and R. H. Cole, J. Chem. Phys., 1941, 9, 341-351.

84. Y.-N. Guo, G.-F. Xu, Y. Guo and J. Tang, Dalton Trans., 2011, 40, 9953-9963.

85. M. Atzori, E. Morra, L. Tesi, A. Albino, M. Chiesa, L. Sorace and R. Sessoli, Journal of the American Chemical Society, 2016, 138, 11234-11244.

86. R. Boča, C. Rajnák, J. n. Moncol, J. n. Titiš and D. a. Valigura, Inorg. Chem., 2018, 57, 14314-14321.

87. J. Miklovič, D. Valigura, R. Boča and J. Titiš, Dalton Trans., 2015, 44, 12484-12487.

88. C.-Y. Lin, T. Ngendahimana, G. R. Eaton, S. S. Eaton and J. M. Zadrozny, Chemical Science, 2019, 10, 548-555.

89. F. Aquilante, J. Autschbach, R. K. Carlson, L. F. Chibotaru, M. G. Delcey, L. De Vico, I. Fdez. Galván, N. Ferré, L. M. Frutos, L. Gagliardi, M. Garavelli, A. Giussani, C. E. Hoyer, G. Li Manni, H. Lischka, D. Ma, P. Å. Malmqvist, T. Müller, A. Nenov, M. Olivucci, T. B. Pedersen, D. Peng, F. Plasser, B. Pritchard, M. Reiher, I. Rivalta, I. Schapiro, J. Segarra-Martí, M. Stenrup, D. G. Truhlar, L. Ungur, A. Valentini, S. Vancoillie, V. Veryazov, V. P. Vysotskiy, O. Weingart, F. Zapata and R. Lindh, J. Comput. Chem., 2016, 37, 506-541.

90. A. N. M., Principles of electron spin resonance, Prentice Hall, 1993.

91. H. Husein Mor, H. Weihe and J. Bendix, J. Magn. Reson., 2010, 207, 283-286.

92. D. Ganyushin and F. Neese, J. Chem. Phys., 2006, 125, 024103.

93. F. Neese, WIRES Comput. Mol. Sci., 2012, 2, 73-78.

94. S. Grimme, J. Chem. Phys., 2013, 138, 244104.

95. C. Bannwarth and S. Grimme, Comput. Theo. Chem., 2014, 1040-1041, 45-53.

96. S. Hirata and M. Head-Gordon, Chem. Phys. Lett., 1999, 314, 291-299.

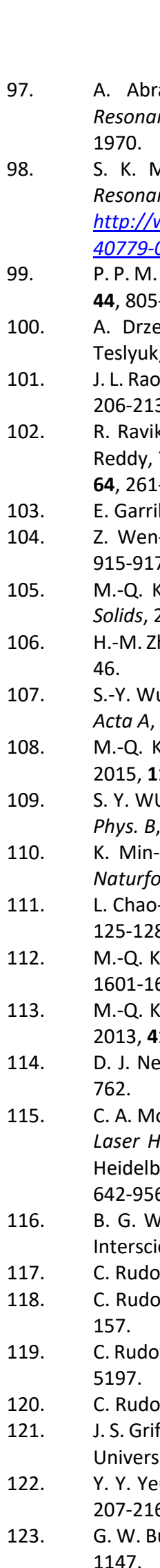

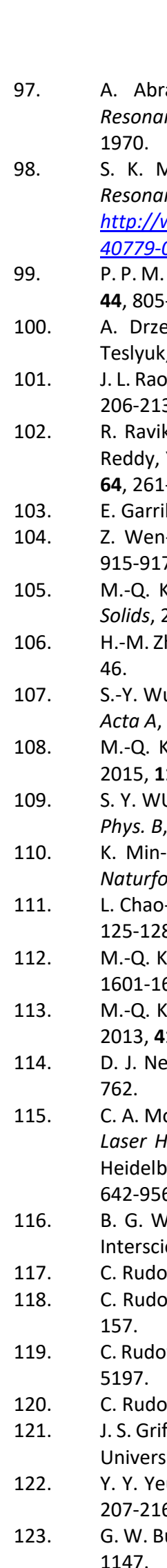

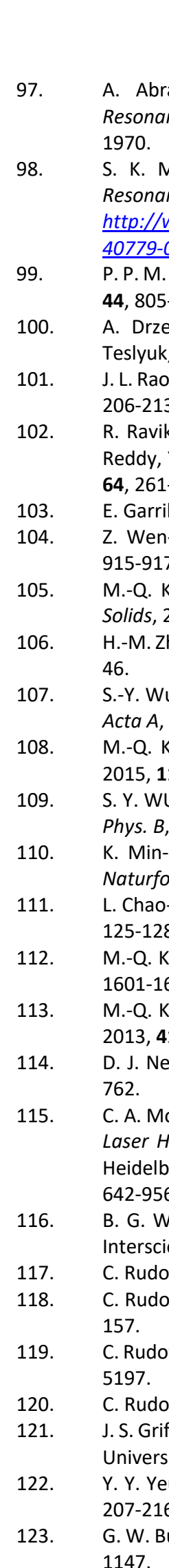

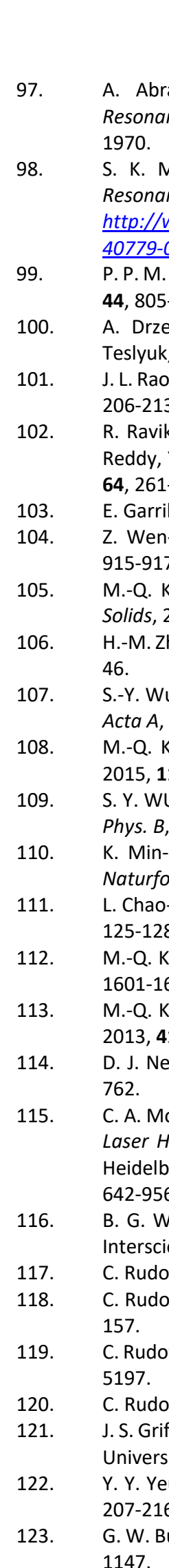

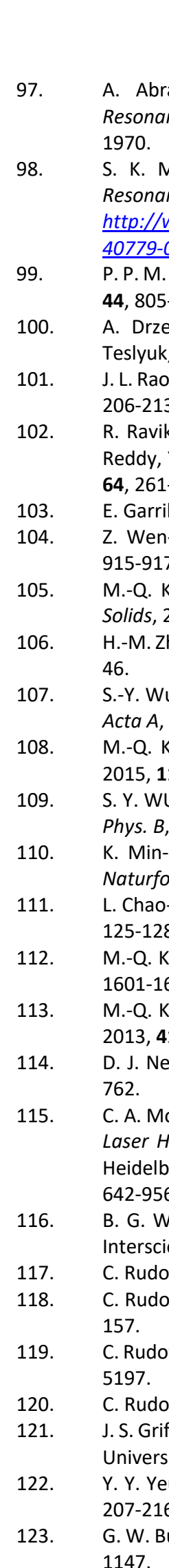

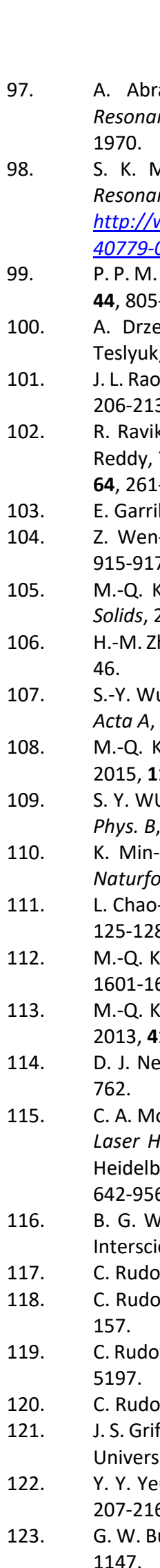

103.

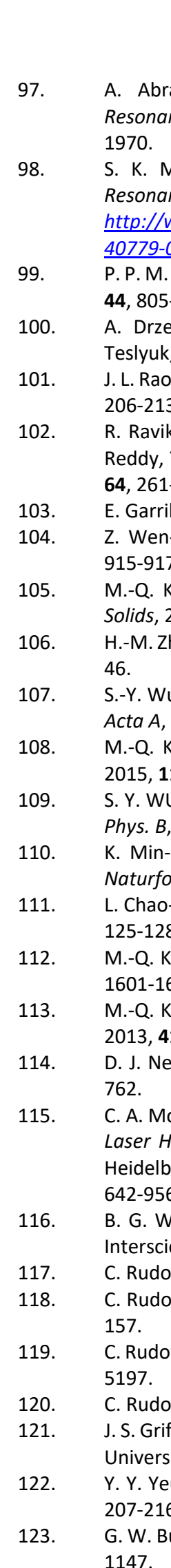

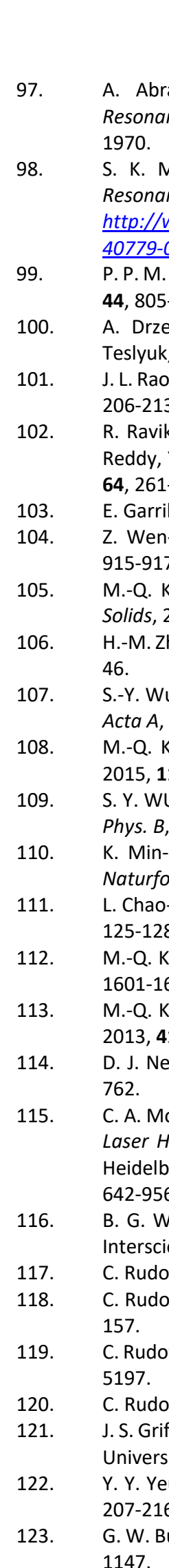

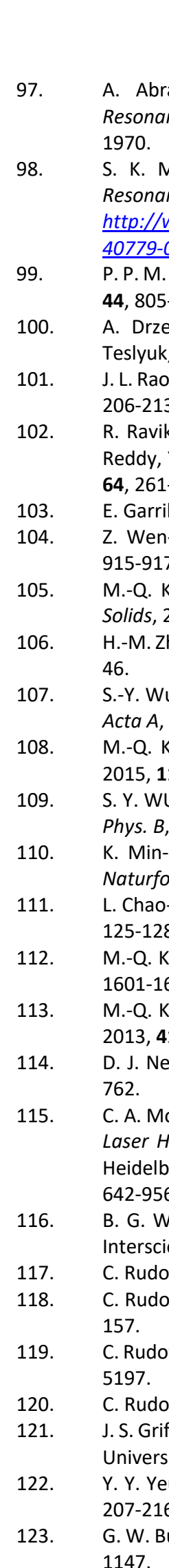

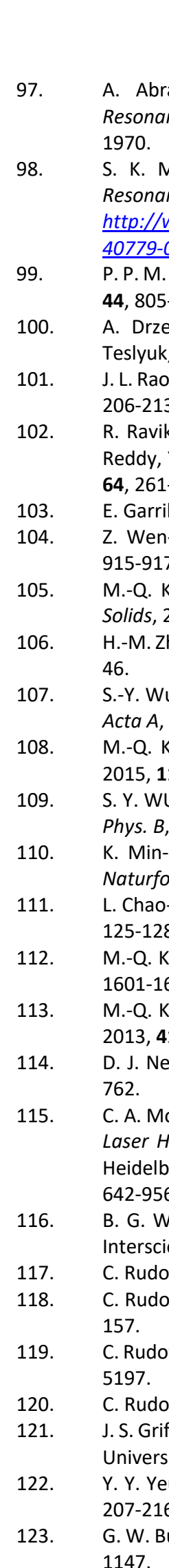

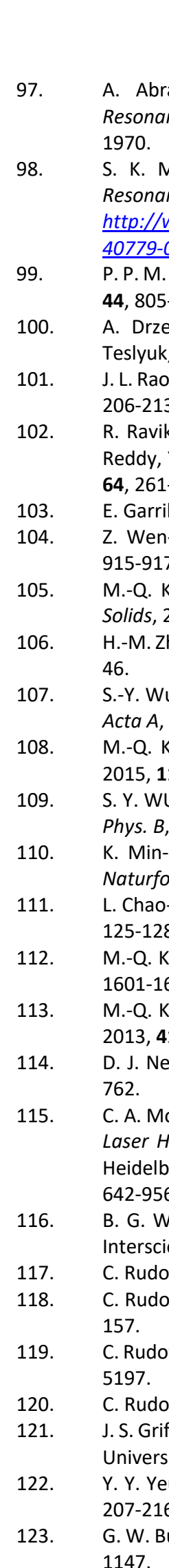

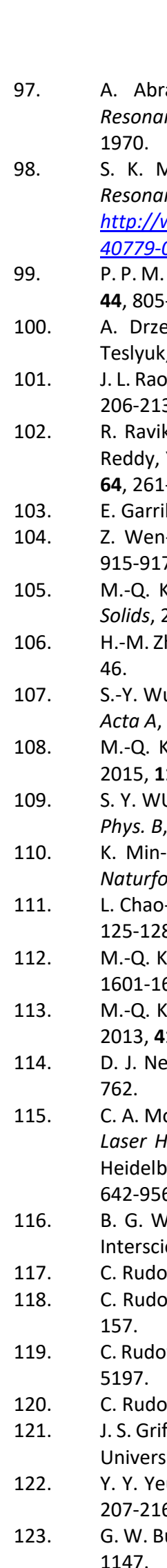

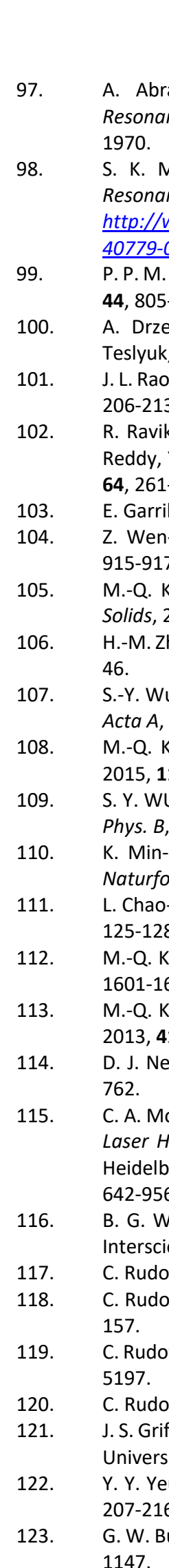

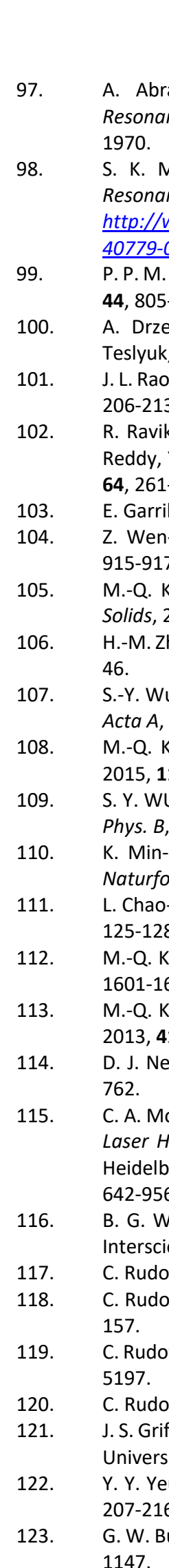

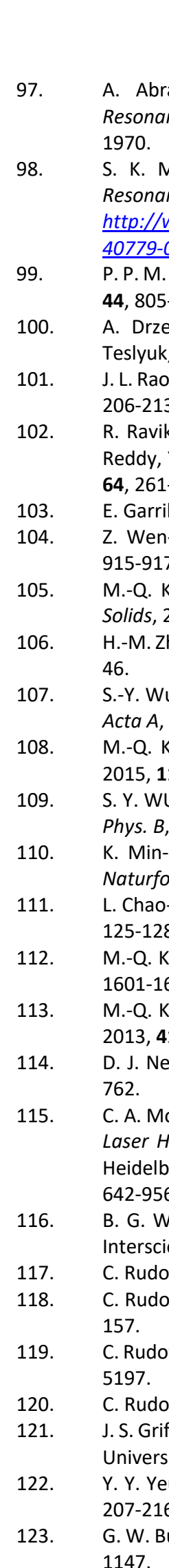

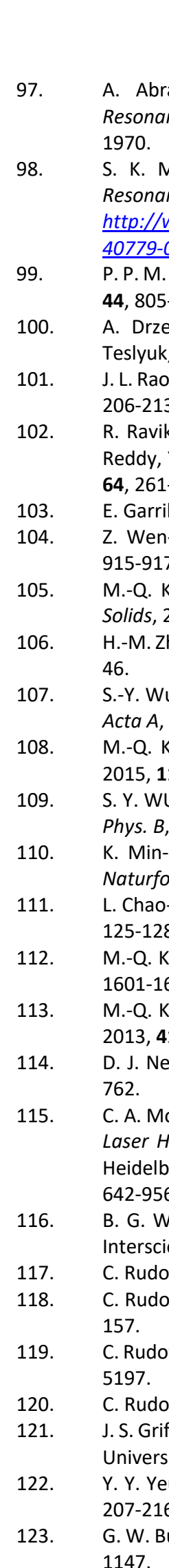

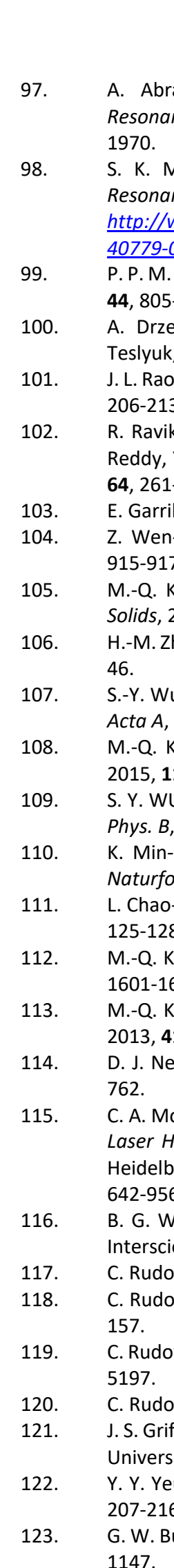

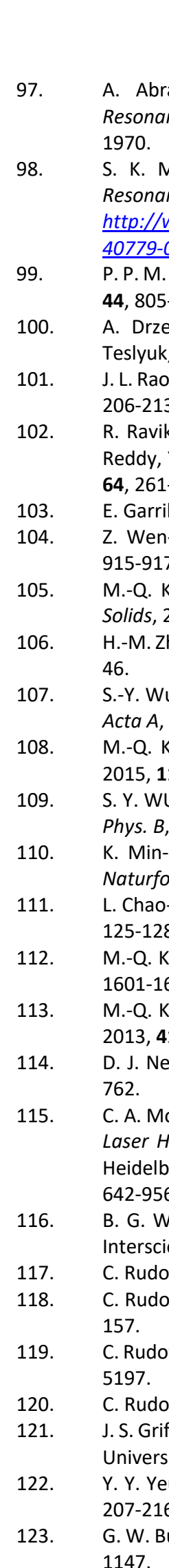

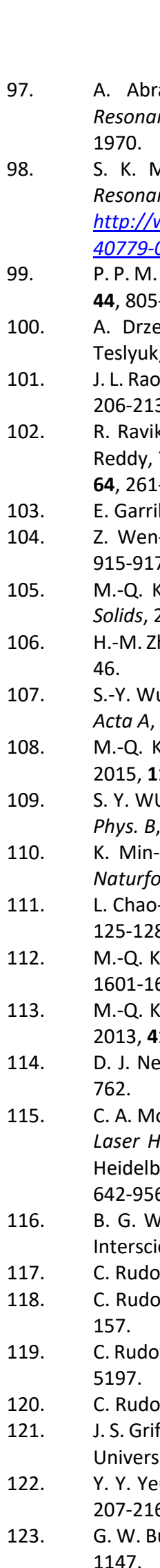

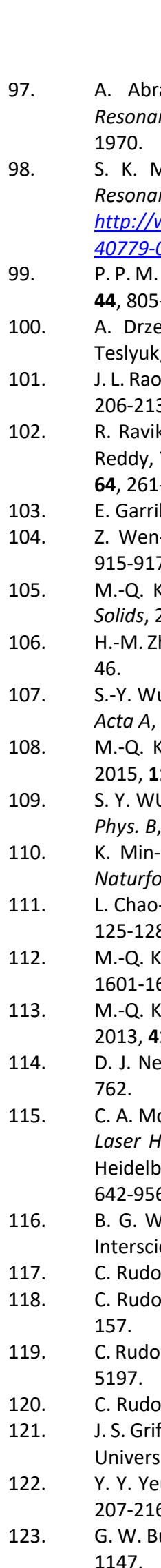

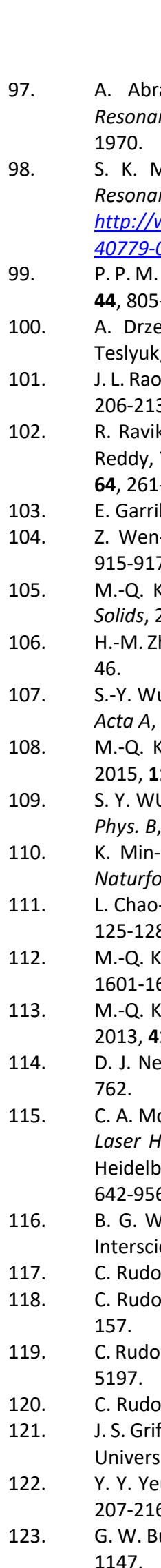

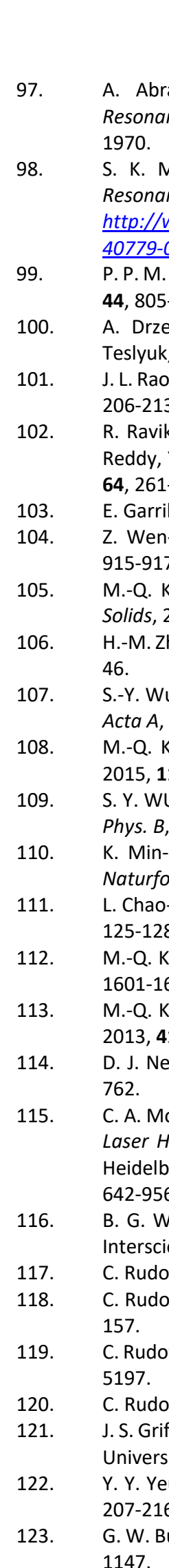

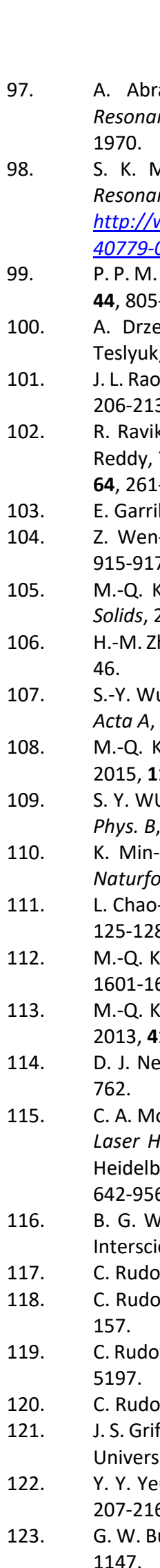

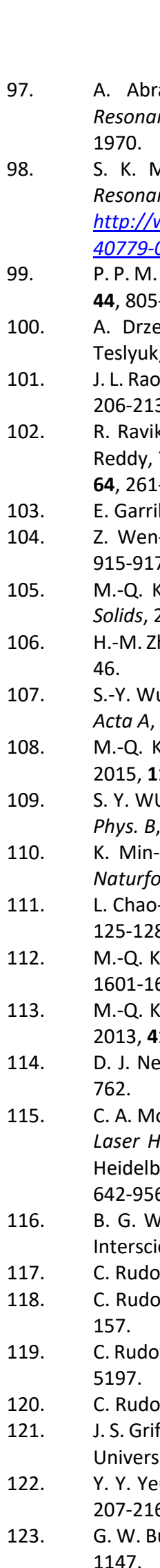

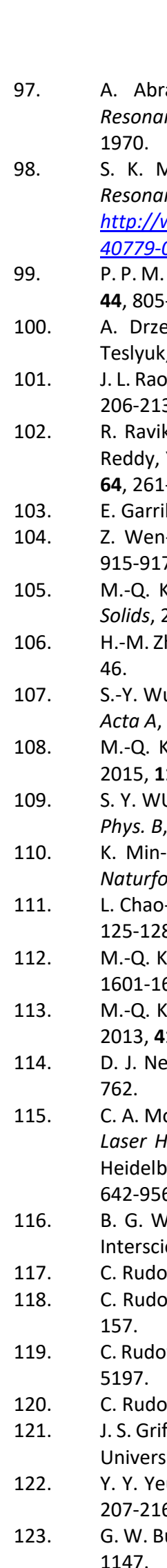

124.

125. 1970. 46 157.

5197.

1147.
A. Abragam and B. Bleaney, Electron Paramagnetic Resonance of Transition Ion, Clarendon Press, Oxford,

. K. Misra, Ed. Multifrequency Electron Paramagnetic Resonance; Erratum S.K. Misra, C. Rudowicz, http://www.wiley-vch.de/publish/dt/books/ISBN3-52740779-0/. Wiley-VCH, Weinheim 2011.

P. P. M. Valko, S. Biskupič, and M. Mazúr, Chem. Pap., 1990, 44, 805-813.

A. Drzewiecki, B. Padlyak, V. Adamiv, Y. Burak and I. eslyuk, Nukleonika, 2013, 58, 379--385.

Rao, G. Sivaramaiah and N. Gopal, Physica B, 2004, 349, 206-213.

R. Ravikumar, R. Komatsu, K. Ikeda, A. Chandrasekhar, B. Reddy, Y. Reddy and P. S. Rao, J. Phys. Chem. Solids, 2003, 64, 261-264.

. Garribba and G. Micera, J. Chem. Educ., 2006, 83, 1229.

Z. Wen-Chen and W. Shao-Yi, Z. Naturforsch., 2000, 55, 915-917.

M.-Q. Kuang, L.-D. Wang and S.-K. Duan, J. Phys. Chem. Solids, 2017, 111, 41-46.

H.-M. Zhang and X. Wan, J. Non-Cryst. Solids, 2013, 361, 43-

U, H.-M. Zhang, P. Xu and S.-X. Zhang, Spectrochim. Acta A, 2010, 75, 230-234.

M.-Q. Kuang, S.-Y. Wu, G.-L. Li and X.-F. Hu, Mol. Phys., 113, 698-702.

Phys. B, 2007, 21, 3250-3253.

n-Quan, W. Shao-Yi, H. Xian-Fen and S. Bo-Tao, Z. Naturforsch. A, 2013, 68, 442-446.

Chao-Ying, H. Ying and Z. Xue-Mei, Physica B, 2015, 456, 125-128.

M.-Q. Kuang, S.-Y. Wu and H.-M. Zhang, Optik, 2012, 123, 601-1604.

M.-Q. Kuang, S.-Y. Wu, X.-F. Hu and B.-T. Song, Physica B, 2013, 417, 13-16.

D. J. Newman and B. Ng, Rep. Prog. Phys., 1989, 52, 699Heidelberg, Berlin, Heidelberg, 1992, DOI: 10.1007/978-3642-95686-7_1, pp. 1-2.

B. G. Wybourne, Spectroscopic Properties of Rare Earths, Cerscience Publishers, 1965

C. Rudowicz and Q. Jian, Comput. \& Chem., 2002, 26, 149-

C. Rudowicz and P. Gnutek, Physica B, 2010, 405, 113-132. J. S. Griffith, The theory of transition-metal ions, Cambridge University Press, 1964.

207-216.

M. Karbowiak, C. Rudowicz and P. Gnutek, Opt. Mater., 2011, 33, 1147-1161.

M. Karbowiak, P. Gnutek and C. Rudowicz, Chem. Phys., 2012, 400, 29-38. 
126. M. Kozanecki, C. Rudowicz, H. Ohta and T. Sakurai, J. Alloys Compd. , 2017, 726, 1226-1235.

127. M. Kozanecki and C. Rudowicz, J. Magn. Magn. Mater. , 2020, 493, 165670.

Insert Table of Contents artwork here

Modular organic scaffold for magneto-structural correlation studies

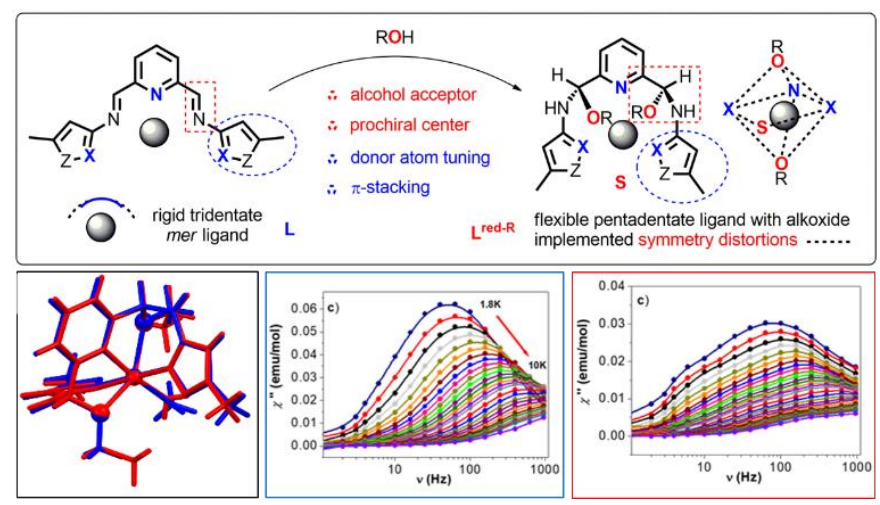

Novel organic scaffold that would allow to gain insight into how subtle structural differences affect the slow magnetic relaxation in $S=1 / 2$ systems. 